Portland State University

PDXScholar

1990

\title{
When older mothers work : adult children's perceptions of maternal employment effects Christine B. Nelson
}

Christine B. Nelson

Portland State University

Follow this and additional works at: https://pdxscholar.library.pdx.edu/open_access_etds

Part of the Psychology Commons

Let us know how access to this document benefits you.

Recommended Citation

Nelson, Christine B., "When older mothers work : adult children's perceptions of maternal employment effects Christine B. Nelson" (1990). Dissertations and Theses. Paper 4110.

https://doi.org/10.15760/etd.5994

This Thesis is brought to you for free and open access. It has been accepted for inclusion in Dissertations and Theses by an authorized administrator of PDXScholar. Please contact us if we can make this document more accessible: pdxscholar@pdx.edu. 
AN ABSTRACT OF THE THESIS OF Christine B. Nelson for the Master of Science in Psychology presented March 2, 1990.

Title: When Older Mothers Work: Adult Children's Perceptions of Maternal Employment Effects

\section{APPROVED BY MEMBERS OF THE THESIS COMMITTEE:}

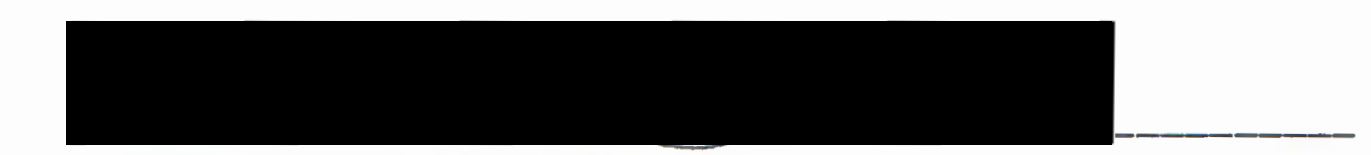

Cathleen L. Smith, Chair

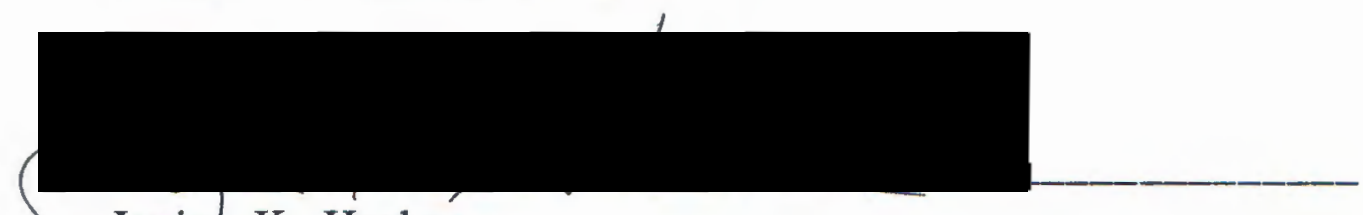

Janice K. Haaken

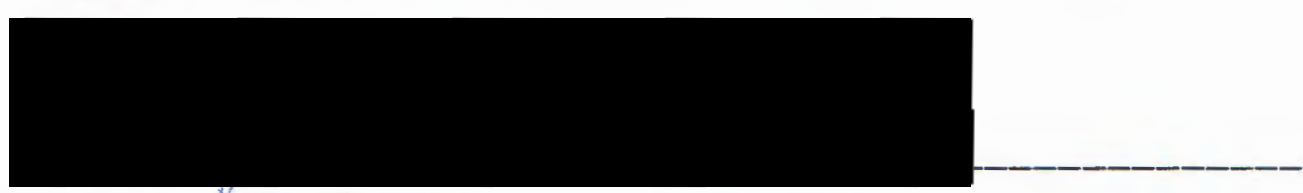

Margaret B. Neal

The effects of maternal employment on the young child have been examined for over 50 years. This research focuses on perceived maternal employment effects at a later point in the family life cycle: when mother is older and children are grown. Thirty-two poverty level women aged 56-83 ( $M=66.4$ years) and their adult sons $(\underline{n}=16)$ and daughters $(\underline{n}=16)$ were independently interviewed. 
All of the older women were paid workers or "stipended volunteers" who were employed part time (20 hours a week) in child care, clerical, or other service jobs. They had a variety of work histories; all were widowed or divorced.

This thesis focused on the interviews with the older employed mothers' adult children, who ranged in age from 23 to 63 (M=37 years). They were asked a number of open-ended questions designed to elicit their views of: how their mother had been affected by her work, whether or not her working affected time spent together or patterns of familial help, and how their relationship with their mother had been impacted as a result of her work. Following transcription of the tape-recorded interviews, half of the interviews were used to identify recurring themes which were then operationally defined, with examples, in a training manual. Using the manual, two trained coders coded all interviews. Reliability, assessed by computing Cohen's Kappa on half of the interviews, ranged from .74 to 1.00 , with an average reliability of .91 .

The content analysis yielded 21 different themes, many of which paint a portrait of employment in poor older women as having largely salutary consequences for themselves and for their families. Work was associated with positive affect/good morale in the older mother (mentioned by $81 \%$ of the sons and daughters). In addition to providing the mother with structure or something to do (75\%), financial independence (69\%), and a sense of purpose or usefulness (38\%), work was seen as having direct effects on the mother-child relationship. Some adult children (38\%) stated outright that their 
relationship with their mother had been improved as a result of her working. Over half (56\%) saw their mother's work as promoting social-emotional independence, an opportunity for her to form new attachments and interests outside of her family. Many of the adult children expressed a sense of relief that the emotional burden had been shifted away from them as a result of their mother's work. Work by the older woman was also seen as relieving the child of financial obligations $(28 \%)$, and as leading to improved communication between mother and child by providing topics of conversation and a basis for shared understanding (41\%).

The older mother's employment also had problematic elements. Forty-four percent of the adult children noted that their mother's work was hard on her, creating physical or emotional stress. Many of the adult children (50\%) indicated that they spent less time or had fewer visits with their mothers as a result of her working; a small number $(16 \%)$ mentioned that she was less available for care of children or great-grandchildren.

This research extends the maternal employment literature by focusing on the older working mother and showing that her employment had largely positive ramifications not only for the woman herself, but also for her relationship with her adult children. 
WHEN OLDER MOTHERS WORK: ADULT CHILDREN'S PERCEPTIONS OF MATERNAL EMPLOYMENT EFFECTS

\author{
by \\ CHRISTINE B. NELSON
}

A thesis submitted in partial fulfillment of the requirements for the degree of

\author{
MASTER OF SCIENCE \\ in \\ PSYCHOLOGY
}

Portland State University

1990 
TO THE OFFICE OF GRADUATE STUDIES:

The members of the committee approve the thesis of Christine B. Nelson presented March 2, 1990.

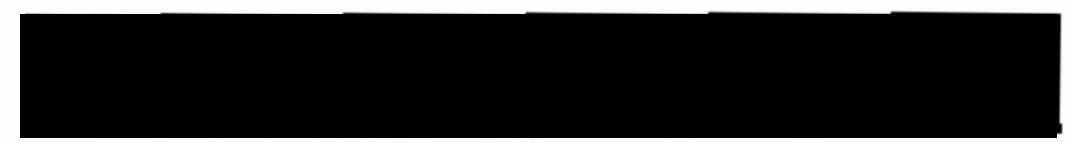

Cathleen L. Smith, Chair

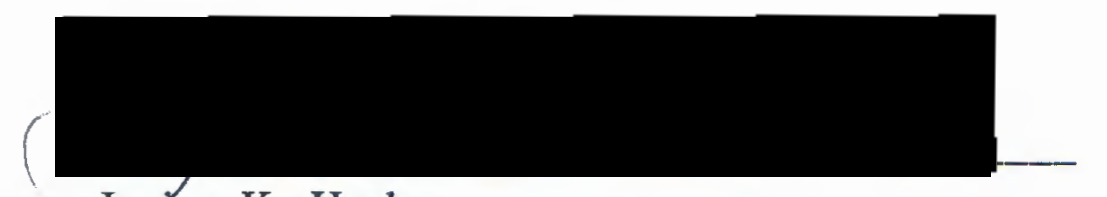

Janice K. Haaken

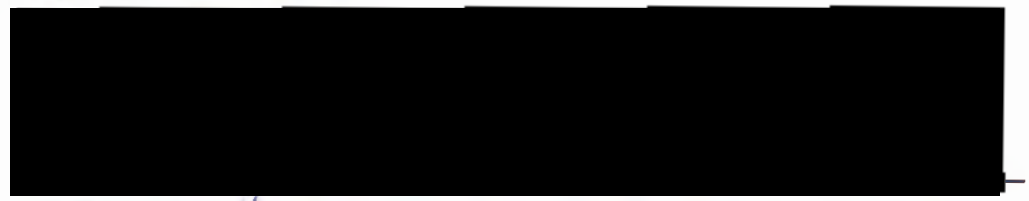

Margaret $\mathrm{B}$. Neal

\section{APPROVED:}

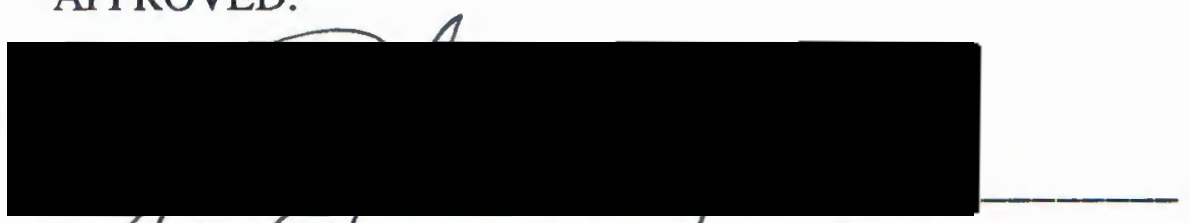

Roger Jenfin \&s, Chair, Department of Psychology

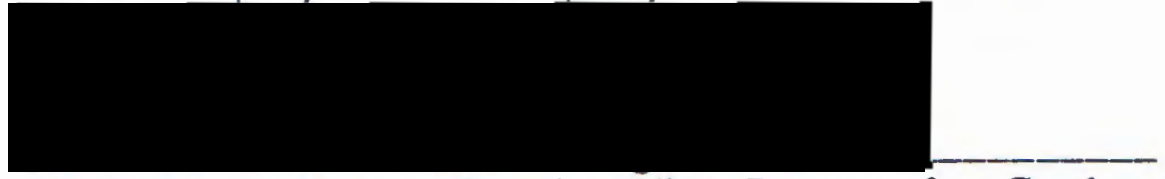

C. William Savery, Interim Vice Provost for Graduate Studies and Research 


\section{ACKNOWLEDGEMENTS}

I would like to express my appreciation for the assistance and support of the many people who made this study possible:

To my advisor and committee chair, Dr. Cathleen L. Smith, whose guidance, suggestions, and encouragement were greatly appreciated; and to the members of my committee, Dr. Janice $\mathrm{K}$. Haaken, Dr. David Cressler, and Dr. Margaret B. Neal, who each contributed their time and energy to the accomplishment of this study.

To Frank Hales, Director of the Foster Grandparents Program, and to Linda Pellate-Carson, Director of the Senior Citizens Community Employment Program for their support and cooperation in facilitating the recruitment process for the study; and to the adult children of the older women from these programs who served as subjects.

To Connie Whipple and Teresa Dobles who were accomplished as interviewers and supportive as friends.

To Jill Strasser and Julie Reynolds who were involved in every phase of this study from from interviewing to code formulation to the coding process itself.

To Julie Liberman who sorted and computerized the data. 
To Carolyn Wright, who despite several less than ideal settings, was able to decipher and transcribe the sometimes inaudible tape recordings of the interviews.

To Dr. Cord B. Senstake, whose help with the statistical computer program proved invaluable.

Finally to my family and friends, and especially to my husband, whose help and emotional support have made it possible for me to pursue my graduate education.

I thank you all. 


\section{TABLE OF CONTENTS}

PAGE

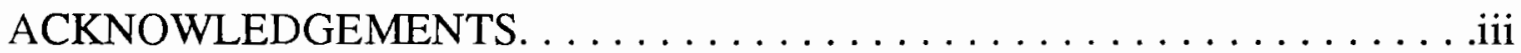

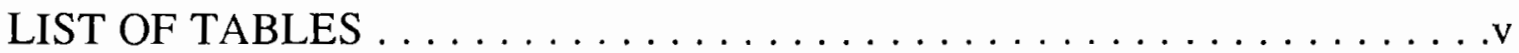

\section{CHAPTER}

I INTRODUCTION $\ldots \ldots \ldots \ldots \ldots \ldots \ldots \ldots \ldots \ldots \ldots \ldots \ldots$

Intergenerational Patterns of Aid and Support . . . . . . .2

The Work-Family Linkage: Effects of Older Person's

Labor Force Participation on Intergenerational

Patterns of Aid and Support . . . . . . . . . . . .

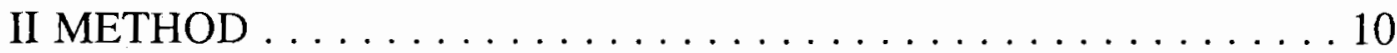

Respondents . .....................10

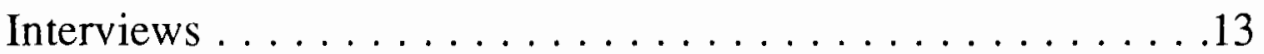

Theme Formulation and Coding . . . . . . . . 18

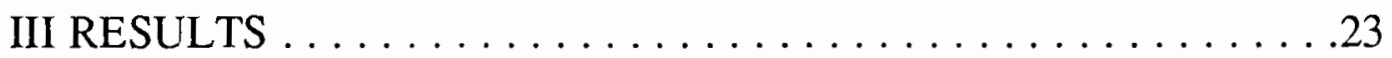

Effects of Work on Mother and Her Family:

Positive Themes ..................... 25

Effects of Work on Mother and Her Family:

Negative Themes .......................... . . . 
Effects of Work on Mother and Her Family:

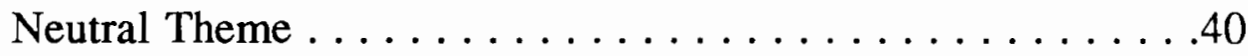

Themes in Context . . . . . . . . . . . . . 41

Quantitative Analyses ................... . . . . . .

Effects of Work on Older Women in General . . . . . . . . .47

IV DISCUSSION $\ldots \ldots \ldots \ldots \ldots \ldots \ldots \ldots \ldots \ldots \ldots \ldots \ldots \ldots \ldots$

Limitations of this Study. . . . . . . . . . . . 65

Areas for Future Research. . . . . . . . . . . . . . 68

REFERENCES ........................ 70

APPENDICES

A ADULT CHILD INTERVIEW FORM . . . . . . . . . .73

B TRAINING MANUAL: WORK EFFECTS ON MOTHER AND

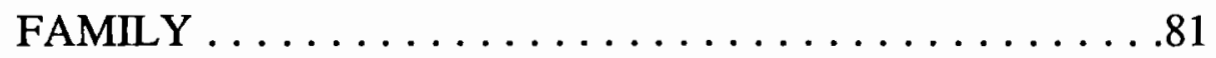




\section{CHAPTER I}

\section{INTRODUCTION}

Women in their later years are taking on new roles and responsibilities that may have far-reaching effects on their lives and the lives of their families. Current and projected trends in employment indicate that there will be increasing numbers of older persons entering the work force in the future (McConnell, 1980). Even now women age 55 and over account for 4 of every 10 older workers (Herz, 1987). These older workers, supporting a trend away from mandatory retirement, are interested in alternative work options as a means of extending their work lives (Fleisher, 1981). Among all older workers, but particularly among women, part-time voluntary or paid employment is the option most preferred (Usher, 1980).

The trends toward early retirement, a decrease in the numbers of young and middle aged workers, and rapid growth in service industries will provide most of the opportunities for part-time work (Deutermann \& Brown, 1978). In fact, the participation of women in service work will account for almost the entire gain in labor force participation over the next few decades (Morrison,1983). This shift towards service and technical work in conjunction with increasing levels of education may mean a longer working life for older individuals in the future (Soldo \& Agree, 1988). These changes in the labor 
force, coupled with projected demographic trends, will have important ramifications for both older women and their families.

How will the fact that older mothers are in the work force affect intergenerational patterns of support and aid? Much has been written about the impact of work on family life for women in their childbearing years, yet little attention has been given to the effects of work on older women and their families. Clearly the involvement of older women in work and the potential repercussions of this involvement need to be examined.

The present study is part of a larger comprehensive study examining older women in the work force, and how their work force participation affects patterns of intergenerational aid and support in the work place and within the family. As part of this larger project, older employed women, their younger women co-workers, and the older women's adult sons and daughters were interviewed. The research reported here focuses on the effects of maternal employment as perceived by the adult sons or daughters of the older working women.

\section{INTERGENERATIONAL PATTERNS OF AID AND SUPPORT}

It is a myth that intergenerational help within families does not exist. In reality, familial aid between generations is not uncommon in American society. In fact, in contrast to earlier times adult children currently provide more assistance, often of a very demanding nature, over longer periods of time than they did in the past 
(Brody, 1985). Shanas (1982) found that family exchanges serve different emotional and instrumental needs across generational lines. These needs are relevant to aspects of lifelong experience in addition to being influenced by ongoing, individual developmental changes (Kuypers \& Bengston, 1984).

Intergenerational needs and exchanges are framed in terms of interdependence. Relationships between family members are most likely to be optimal when each family member is perceived as available as a mutual resource. Each generation was found to endorse egalitarian sharing of roles by the sexes fulfilling expectations of equity rather than equality (Brody, Johnsen, Fulcomer, \& Lang, 1985).

\section{Older Parents' Support to Adult Children}

There is widespread documentation in the literature concerning the dependency needs of frail elderly people, or those in poor health. These older men and women are all too often depicted as being passive recipients, reliant upon the services of others for support and care. This approach tends to overstate the extent to which older individuals are non-reciprocating beneficiaries of the energies and resources of those closest to them. Contrary to these images, older men and woman who are not ill or frail contribute substantially to their social networks by providing services, engaging in reciprocal exchanges, and helping others, both young and old, cope with the stressful events in their own lives (Stueve, 1985). 
Bild \& Havighurst (cited in Mancini, 1984) found that help provided by older persons to their adult children included advice on life's problems, advice on jobs and business, housekeeping assistance, household maintenance, financial support, gift-giving, assistance with shopping and running errands, child care, and care in time of illness. Although research suggests that there are wide variations in family help patterns affecting the amounts and types of aid given, elderly parents remain an important part of their children's lives (Stueve,1982). How these patterns of assistance would be affected by the increased participation of older individuals in the work force, however, has not been addressed and is the focus of the present study.

\section{Adult Children's Support to Older Parents}

Elderly people have considerable contact with their adult children. About three-fourths report having face-to-face contact with a middle aged child on a weekly or semi-weekly basis. When face-toface contact is not possible, other means of staying in touch are relied upon (Troll, Miller \& Atchley, cited in Mancini, 1984). Cicirelli (1983) reported that nine out of ten children felt "close" or "very close" to their older fathers and mothers. When the need arises in the elderly person's life, the adult offspring are most likely to provide assistance. Adult children often provide help in illness or crises as well as in other areas such as home repairs, housework, gifts, and negotiations with various bureaucracies (Cicirelli, 1981). 
Conclusive evidence exists that older persons expect help from their families. Older people with high expectations of children are more likely to place greater demands on them than those with lesser expectations (Quinn, 1984). In a study by Matthews (1979), adult offspring served as the primary source of "moral support" and needed services for their aging widowed mothers. However, the types of services provided by adult children to their elderly mothers differed across gender lines.

Gender Differences in Support to Elderly Parents. Differential gender roles are documented in the "informal social support" literature dealing largely with declining and dependent elderly persons. Yet even among healthy, active older persons, there is evidence that adult sons and daughters contribute in important ways, both emotionally and instrumentally, to their well-being. .Women are often expected to provide help to their aging parents because it is seen as an extension of their societal roles as caregivers. Generally, elderly women depend on the daughter (and in some cases the daughter-inlaw) who has the fewest obligations (i.e., who is not employed outside the home, or who works on a part time basis, or has fewer demands on her time) to provide this needed assistance (Brody et al., 1985). Being in this caregiving capacity often results in placing pressure on the adult who serves as the primary provider. The resultant "role strain" (Lakosa, cited in Fischer, 1985) is a relative concept related to expectations experienced by the middle-aged daughter in response to the perceived and/or actual needs of her elderly parent. With recent increases in women in the labor force, a large majority of 
these middle-aged daughters, and daughters-in-law, are employed outside the home. Consequently, they are being asked to assume the role of caregiver and paid worker, often in addition to their roles of wives, homemakers, mothers and grandmothers (Brody, 1985).

Although Brody and others (e.g., Horowitz, 1981; Lurie, 1981;

Shanas, 1968 cited in Stewart \& Smith, 1983) have reported that women are the primary caregivers to impaired elderly family members, men are also involved in this capacity. In one of the few studies examining the effect of caregiver gender, Horowitz (1981 cited in Stewart \& Smith, 1983) found that sons undertook the role of primary caregiver to an elderly parent by default (i.e., when they were only children or in male-only sibling networks). Robinson and Thurnher (1979) found that men supplied different types of help in their roles as caregivers than women did. Sons' contributions proved to be more instrumental and economic (e.g., financial management, financial assistance, and help in dealing with bureaucratic organizations), whereas daughters' contributions were through emotional input and service provision.

Men may also be able to remove themselves to a greater extent emotionally and physically from their parents. Compared to women, men seem to experience less guilt, and to accept more readily the fact that they are not responsible for the emotional well-being of their parents (Robinson \& Thurnher, 1979). 


\section{THE WORK-FAMILY LINKAGE:}

EFFECTS OF OLDER PERSONS' LABOR FORCE PARTICIPATION ON INTERGENERATIONAL PATTERNS OF AID AND SUPPORT

Although there is a wide body of research on the "spillover effect" from work to family life for younger workers (Nieva, 1985), there is virtually no information on the impact of the work experience of older persons on family ties. In particular, virtually nothing is known about the role that elderly women's labor force participation may play in altering patterns of intergenerational aid and support. Converging lines of evidence from several sources, however, suggest potential fruitful lines of inquiry. In the first place, it is clear that in general, paid work has salutary effects on the lives of women. Coleman and Antonucci (1985) found that paid work was the sole significant predictor of a sense of self-esteem in a nationwide sample of middle-aged women, correlating with a lack of psychological anxiety and physical health. Troll (1982) also found that work provided a major source of identity, independence and life satisfaction for middle-aged women.

One might expect to see the same benefits for older women who are involved in paid or volunteer work, and indeed this seems to be the case. Social gerontologists agree on the health, social, and emotional benefits of volunteer programs for older persons (Payne \& Bull, 1985). There is also a growing emphasis on the value of parttime work for individuals of retirement age (ACTION, 1984; 
Payne \& Bull, 1985). For example, a three year longitudinal study of the Foster Grandparents Program (ACTION, 1984) found that the program participants not only improved their economic resources but their social resources as well. Involvement in the program was also associated with improved mental health, with slowing the deterioration of physical health, and with better overall functioning. Participation in the Foster Grandparent Program was even found to decrease the mortality rate of the elderly persons involved.

The question remains, however, whether or not these positive effects extend into the older working woman's family life. Older women who are involved in paid work may experience a greater sense of self-worth and economic independence. In addition they may gain exposure to a wider variety of emotionally satisfying relationships. Elderly women's work force participation may serve to decrease needs for both the instrumental and affective support provided by their adult children. Rather than having to rely on the family as her sole means of financial and/or socioemotional support, the older woman will have other social and economic resources available. This may affect her children's perceptions of her need for various kinds of support.

Despite the preponderance of positive implications of older woman's participation in the work force, there may be negative repercussions as well. With her increased labor force participation, the older woman will also experience an increase in the demands on her time and energy. As a consequence of these factors, she may have less time to devote to her family and therefore be unable to 
provide the amount of affective and instrumental support that she did prior to her involvement in the work force. 


\section{CHAPTER II}

\section{METHOD}

\section{RESPONDENTS}

\section{Adult sons and daughters}

The respondents $(n=32)$ were adult sons and daughters of the older working women who were part of the larger study on intergenerational relations described earlier. As can be seen in Table I, these adult children, half sons $(n=16)$, half daughters $(n=16)$, ranged in age from 23 to 63 . Seventeen $(53.1 \%)$ were employed in blue collar/skilled worker occupations, eleven (34.4\%) in a professional/managerial level, and one was self-employed. Three daughters, $9.4 \%$ of the total sample, were not employed outside the home. The majority of the respondents had completed twelve years of education (mean=12.9 years), with the sons averaging 13.3 years and the daughters 12.3 , respectively. Nineteen (59.4\%) were married at the time of the interview, seven (21.9\%) divorced, and six (18.8\%) had never married. The majority $(96.9 \%)$ of the respondents were white.

Because the adult sons and daughters who were interviewed for this study were selected on the basis of their relationship to their mother, these older working women will now be discussed in some detail. 
TABLE I

\section{ADULT CHILDREN OF OLDER WORKING MOTHERS CHARACTERISTICS OF RESPONDENTS \\ $(n=32)$}

$\begin{array}{lccc}\text { Age } & \begin{array}{c}\text { Sons } \\ (\mathrm{n}=16)\end{array} & \begin{array}{c}\text { Daughters } \\ (\mathrm{n}=16)\end{array} & \begin{array}{c}\text { Total } \\ (\mathrm{n}=32)\end{array} \\ \text { Range } & 27-63 & 23-48 & 23-63 \\ \text { Mean } & 37.9 & 35.4 & 37 \\ \text { St. Dev. } & 8.19 & 7.12 & 7.67\end{array}$

Occupation

Blue collar/

Skilled wker.

$10(62.5 \%)$

$7(43.8 \%)$

$17(53.1 \%)$

Professional/

Managerial

$6(37.5 \%)$

$5(31.3 \%)$

$11(34.4 \%)$

Self Employed/

Sm. Bus. Owner

Does not work outside home

$1(6.3 \%)$

$1(3.1 \%)$

$3(9.4 \%)$

3 (9.4\%)

Education

Mean yrs.

13.3 yrs.

12.3 yrs.

12.9 yrs.

Marital Status

Married

$10(62.5 \%)$

$9(56.3 \%)$

$19(59.4 \%)$

Divorced

1 (6.3\%)

$6(37.5 \%)$

5 (31.3\%)

$1(6.3 \%)$

7 (21.9\%)

Never married

Age of Mother

Range

Mean

St. Dev.
57-83

65.6

7.3
56-82

65.3

7.7
56-83

65.4

7.5 


\section{Older women}

The older women $(n=32)$ were individuals over the age of 55 who worked or were "stipended" volunteers for 20 hours per week in a non-managerial capacity in a social service setting. As seen in Table II, these women ranged in age from 56 to 83, with an average age of 66.4 years. Fourteen $(43.8 \%)$ were widows at the time of the interview, fourteen (43.8\%) were divorced, and four (4.2\%) were separated. Nine $(28.1 \%)$ had previously been employed for fifty percent or more of their past work life in a social service position, twenty-one $(65.6 \%)$ of these older women workers had previously held clerical, technical/business jobs, and one (3.1\%) was selfemployed. One (3.1\%) older woman's prior position did not fall under our predetermined categories and was therefore categorized as "other". Of the older working women's late, estranged or exhusband's past work histories, fifteen (46.9\%) had held blue collar/skilled worker positions for fifty percent or more of their past work life, five $(15.6 \%)$ were either professionals or employed on a managerial level, six $(18.8 \%)$ were self-employed or small business owners, and six (18.8\%) of the husband's past job histories were unavailable. All but one of the older working women were Caucasian.

The directors of two government programs in Portland, Oregon gave permission to recruit participants from their ranks. These programs were chosen to represent two viable work options for older persons: paid employment and paid voluntarism. Women in the Senior Community Service Employment Program (SCSEP), sometimes 
TABLE II

\section{CHARACTERISTICS OF OLDER WORKING WOMEN}

$$
(\mathrm{n}=32)
$$

$\begin{array}{lccc}\text { Age } & \text { FGP } & \begin{array}{c}\text { SCSEP } \\ (\mathrm{n}=16)\end{array} & \begin{array}{c}\text { TOTAL } \\ (\mathrm{n}=32)\end{array} \\ \text { Range } & 65-83 & 56-59 & 56-83 \\ \text { Mean } & 72 & 60.8 & 66.4 \\ \text { St. Dev. } & 5.24 & 3.27 & 4.26\end{array}$

Education

Mean yrs.

12.75

11.16

11.95

Marital Status

\begin{tabular}{|c|c|c|c|c|}
\hline Widowed & $9 \quad(56.3 \%)$ & $5(31.3 \%)$ & 14 & $(43.8 \%)$ \\
\hline Married & --.----- & & & 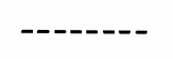 \\
\hline Divorced & $6 \quad(37.5 \%)$ & $8(50 \%)$ & 14 & $(43.8 \%)$ \\
\hline Separated & $1 \quad(6.3 \%)$ & $3(18.8 \%)$ & 4 & $(4.2 \%)$ \\
\hline
\end{tabular}

Husband Occupation

Blue Collar/

Skilled Worker $9(56.3 \%)$

$6(37.5 \%)$

$15(46.9 \%)$

Professional/

Managerial

Self-Employed/
Sm. Bus. Owner 1 (6.3\%)

Unavailable
$1(6.3 \%)$

$4(25 \%)$

$5(31.3 \%)$

$1(6.3 \%)$

$4(25 \%)$

$11(68.8 \%)$

$9(56.3 \%)$

Self-Employed 1 (6.3\%)
Other

\section{5}

Clerical/Tech./

Business

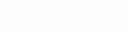

Social Service
$5(15.6 \%)$

$6(18.8 \%)$

$6(18.8 \%)$

$9(28.1 \%)$

$20(62.5 \%)$

$1(3.1 \%)$

$1(3.1 \%) \%)$ 
referred to as the AARP program, are paid employees. Individuals in this program are low-income persons fifty-five years of age or older who work for approximately twenty hours per week at minimum wage in non-profit community service organizations. The goal of SCSEP is to help these women acquire employable skills and a job record to aid in the procurement of permanent (unsubsidized) employment. Women involved in the second work option, the Foster Grandparents Program (FGP), are paid volunteers. These low-income women, sixty years or older, receive a stipend of $\$ 2.20$ per hour (plus transportation, health insurance and a hot meal) for working twenty hours a week providing care for children with special needs in schools, hospitals, and other public and private non-profit agencies.

An attempt was made to recruit older women who were involved in a third work option for older persons: unpaid voluntarism. The director of the Retired Senior Volunteer Program (RSVP) supplied the names of a few women who she believed volunteered a large number of hours each week. However, it was found upon contacting these individuals that none volunteered anywhere near to the criteria required for participation in the study of 20 hours per week as found in the other two groups.

As Table II indicates, the mothers in the FGP program were significantly older $(\underline{t}=6.73, \mathrm{p}<.001)$ than their counterparts in the SCSEP program. This is due in large part to the age requirements of program participation (women in the FGP program must be 60 or older compared to the minimum age of 55 for SCSEP workers). The 
philosophies of these two programs also differ. Although both mandate poverty-level income for participation, SCSEP is a job training program, while FGP is a volunteer program which pays its participants a stipend of $\$ 2.20$ an hour.

\section{INTERVIEWS}

\section{Interviewers}

The interviewers for the data reported here were the author, two other graduate students, and one advanced undergraduate student in Psychology at Portland State University. Half of the interviews were conducted by the author, with the remaining half done by the other three interviewers. Prior to actual data collection, training in open-ended interviewing techniques included extensive practice in interview methods through role playing.

Pilot interviews with persons similar to those in the actual study were also conducted. In addition, interviewers developed the theoretical basis of the study through literature review and ongoing discussion. This enabled the interviewers to listen carefully to the respondents and to pursue the theoretical implications of responses through selective probes.

\section{Procedure}

The name and telephone numbers of adult sons and daughters were supplied by the older working woman as part of the initial recruitment process. Recruitment of the older women took place at the participating programs' (SCSEP and FGP) quarterly meetings, where a 
description of the research was presented and volunteers were solicited. In order to participate in the study, the older woman needed to have one or more children living in the greater Portland metropolitan area, and a younger woman coworker in her twenties or thirties (in conjunction with the related study on intergenerational relations in the work place). In the case of having more than one child, the older woman was asked to designate the child with whom she had the most contact. The exception to this latter requirement arose toward the end of data collection in order to effect the desired number of sons and daughters. Because fewer older women had named sons as the child with whom they had the most contact, we requested from several of the final respondents that the child interviewed be a male, regardless of amount of contact. In three of the instances where a son's participation was requested the request was refused. In one of these cases a daughter was interviewed in place of the son after the mother refused to supply her son's name and telephone number, in another a male only-child refused outright, and in the last case the older women suggested contacting another son, who complied. For all respondents, the adult child was then contacted by telephone in order to determine his/her willingness to participate in the research. 
Interview with Adult Child

The interview with the adult child dealt with family structure and affective relationships as well as patterns of intergenerational family help. Questions pertinent to the data presented here centered around the nature of the older woman's work from her adult offspring's perspective: how her work affected patterns of help between mother and child and amount of time spent with her son/daughter and other family members, and how the adult child felt the mother and the family had been impacted as a result of her work. In addition, the adult child's attitude towards the work of older persons in general was examined: how he/she felt older workers benefited from working and when he/she felt it was not appropriate to employ an older worker. (The complete interview schedule can be found in Appendix A.)

All interviews were conducted between June 1987 and October 1988. The interviews averaged between one and one and one half hours in length and were recorded on audio tape. They were conducted at a setting chosen by the respondent, generally in his/her home. Several respondents preferred to be interviewed in a public place such as a restaurant or their work place, while a few were interviewed at Portland State University. In addition to the recorded information, field notes were written by the interviewers immediately following each interview. These contained off-the-record comments by the respondent as well as descriptions, reflections and perceptions of the interviewer regarding the setting, the respondent, and the interview process. 


\section{THEME FORMULATION AND CODING}

Data collation began after the completion and transcription of the interviews with the adult children and their older employed mothers. The process of theme extraction was carried out by a research team consisting of Dr. Cathleen Smith, the supervisory professor, the advanced undergraduate who served as an interviewer, and the author. Identification of themes was accomplished using half of the interviews from both older mothers and adult children, in order to formulate a coding scheme that would apply to both data sets. Interviews from both groups were selected in order to present a representative cross-section of interviewer, employment program and work setting of older working mother, and gender of adult child. The process of isolating recurring themes was carried out by the research team through careful reading of the transcripts that had been divided into sub-sections. Each of these sub-sections was independently examined by the members of the research team to isolate recurring patterns of response. These response patterns were then compiled and examined to establish thematic classifications. Individual differences among the members of the research team in naming themes or noting their presence were compared and analyzed in order to arrive at a consensual compromise. This process eventuated in the derivation of 23 mutually exclusive and exhaustive themes or codes and their respective operational definitions. The 23 themes were divided for convenience into three conceptual subdivisions: positive themes, 
negative themes, and one neutral theme referring to the fact that the older mother had always worked, (this theme was conceptualized as "neutral" because it could not be clearly identified as positive or negative).

Upon completion of theme extraction and code formulation, the remaining half of the interviews not used in formulating the codes were briefly examined in order to assure that the agreed upon coding scheme classification would apply to these data as well. The resulting data classification scheme was compiled in a manual entitled Work Effects on Mother and Family. This manual (which may be found in Appendix B) contained the 23 themes or codes, their corresponding definitions, and a number of fabricated responses to illustrate each theme similar to actual responses within the interviews.

This instructional manual was then used by two raters to code each of the $(\underline{n}=32)$ transcribed interviews. The raters were an undergraduate honors student and a doctoral student in psychology. Prior to the actual coding process, the raters were trained by Dr. Smith using the instructional manual. Initially the training process entailed the raters familiarizing themselves with the codes and definitions and their corresponding illustrative responses. The fabricated responses were then combined and mixed on a separate sheet of paper, without the codes and definitions, for practice identification. Finally, after the raters felt proficient, they coded two of the actual interviews to complete their training. Between the coding of the two data sets (i.e., adult children and employed mothers), as well as at periodic intervals during the coding of the 
adult child interviews, the two raters met with each other to discuss coding disagreements. However, no revisions or changes were made in the data after the initial coding process.

Raters were instructed to code all themes that occurred in each response unit (a response unit was operationally defined as a verbalization by the respondent uninterrupted by the interviewer). Each theme was coded only once per response unit, regardless of how many times it occurred. Themes were scored in the interview wherever they emerged, but these questions to the adult children elicited the bulk of the codable responses:

How do you think your mother's working has affected her?

Do any of these changes (in adult child's help to mother) seem to be due to her working/volunteering?

How do you think your mother's working/volunteering has affected her relationship in general with you? With other family members? (how has your mother's working affected how you see her?)

Are there any changes (in patterns of mother's help to adult child) that seem to be due to her working/volunteering?

Has your Mother's working/volunteering affected the amount of time she spends with you? With other family members?

In general, do you think working/volunteering is good for older women? How do you think they benefit?

In what situations would it not be appropriate to place older persons as workers or volunteers? 
Do you think older workers/volunteers should get more pay or benefits from the work?

Themes referring to the effects of work on older women in general (elicited for the most part in response to the final three questions listed above) were differentiated from those themes that referred to the specific women in the study by the addition of the letter $\mathrm{G}$ (for general).

Reliability

Reliability between raters, agreement as to whether a particular theme appeared in a particular response unit, was calculated on half of the data ( $\underline{n}=16$ interviews) by means of a Cohen's Kappa for each interview following the coding of the $(\underline{n}=32)$ interviews. Reliability figures ranged from .74 to $1.00(\mathrm{M}=.91)$. In addition, percent agreement between raters for each theme was calculated using all of the interviews for which Kappas had been computed. As seen in Table III, the percent agreement figures for the 23 themes ranged from $60 \%$ to100\%, $(\mathrm{M}=85.8 \%)$. Disagreements between coders were arbitrated by Dr. Smith. 
TABLE III

\section{PERCENT AGREEMENT BETWEEN RATERS MENTIONING EACH of 23 THEMES}

\section{PERCENT}

\section{AGREEMENT} $80 \%$

$89.2 \%$

$87.5 \%$

$88.9 \%$

$100 \%$

$100 \%$

$88.2 \%$

$100 \%$

$75 \%$

$65.9 \%$

$86.7 \%$

$66.7 \%$

$100 \%$

$94.1 \%$

$81.8 \%$

$60 \%$

$83.3 \%$

$100 \%$

$76.6 \%$

$94.4 \%$

$83.3 \%$

\section{THEMES}

Satisfaction-Structure

Satisfaction-Positive-Affect

Satisfaction-Self-Esteem

Satisfaction-Purpose

Satisfaction-Purpose-Serve

Satisfaction-Purpose-Challenge

Satisfaction-Social-General

Satisfaction-Social-Specific ${ }^{a}$

General Work-Derived Independence

Work-Derived Social/Emotional Independence

Work-Derived Financial Independence

Work-Derived Physical Independence

Improved Relations

Time Positive

Improved Communication

Other Esteem

Work-Derived Time Decrease

Work-Derived Visits Decrease

Work-Derived Child care Decrease

Work-Derived Instrumental Decrease ${ }^{a}$

Adult Child's Work

Work-Derived Physical/Emotional Stress

Always Worked 
CHAPTER III

\section{RESULTS}

The interviews with the 32 adult sons and daughters were coded by two raters according to the thematic coding scheme devised by the research team. Following coding, the 32 interviews were entered into a computer using the ETHNOGRAPH program. This was undertaken in order to aid in the data reduction process. The Ethnograph program produced a summary sheet detailing the start and stop line for each theme in each interview. The data presented below are drawn from these summary sheets.

Of the 23 themes identified by the research team in the theme extraction process, 21 were found by the coders to be present in the interviews. Two themes, Satisfaction-Social-Specific, and WorkDerived Instrumental Decrease, were not found in the interviews with the adult children, although they were present in the mothers' interviews. The following presentation describes the 21 themes, listed for convenience in three subdivisions: positive, negative, and neutral. The themes within each subdivision are listed in order from most to least often mentioned, with corresponding definitions and illustrative quotes (percent of total sample mentioning theme is listed in parentheses). Table IV presents a summary of the number and percentage of respondents who mentioned each of the 21 
TABLE IV

\section{NUMBER AND PERCENTAGES OF RESPONDENTS MENTIONING EACH OF 23 THEMES}

\begin{tabular}{|c|c|c|c|}
\hline$\underline{\mathbf{N}}$ & $\underline{\%}$ & POSITIVE & \\
\hline 26 & 81 & SAT-AFF & Satisfaction-Positive Affect \\
\hline 24 & 75 & SAT-STRUC & Satisfaction-Structure \\
\hline 22 & 69 & WIND-PAY & Work-Derived Financial Independence \\
\hline 18 & 56 & W-IND-SE & Work-Derived Social/Emotional Indep \\
\hline 13 & 41 & COMM & Improved Communication \\
\hline 12 & 38 & IMP REL & Improved Relations \\
\hline 12 & 38 & SAT-PUR & Satisfaction-Purpose \\
\hline 11 & 34 & SAT-PUR-SE & Satisfaction-Purpose-Serve \\
\hline 10 & 31 & O-EST & Other Esteem \\
\hline 10 & 31 & SAT-SOC-G & $\underline{\text { Satisfaction-Social-General }}$ \\
\hline 9 & 28 & SAT-EST & Satisfaction-Self-Esteem \\
\hline 5 & 16 & W-IND-PHY & Work-Derived Physical Independence \\
\hline 4 & 13 & TIME-POS & Time-Positive \\
\hline 4 & 13 & W-IND & Work-Derived Independence \\
\hline 3 & 9 & SAT-PUR-CH & Satisfaction-Purpose-Challenge \\
\hline 0 & 0 & SAT-SOC-S & Satisfaction-Social-Specific \\
\hline
\end{tabular}
N $\%$ NEGATIVE
1444 W-STRES Work-Derived Physical/Emotional Stress
1341 W-VIS-DEC Work-Derived Visits Decrease
928 W-TIME-DEC Work-Derived Time Decrease
516 W-CC-DEC Work-Derived Child care Decrease
$3 \quad 10$ AC-WK $\underline{\text { Adult Child's Work }}$
$0 \quad 0$ W-IND $\quad$ Work-Derived Instrumental Decrease

$\frac{\mathbf{N}}{7} \quad \frac{\%}{22} \quad \underline{\text { NEUTRAL }} \quad \underline{\text { Always Worked }}$ 
themes. Those themes that were mentioned in reference to older employed women in general are presented in a later section.

\section{EFFECTS OF WORK ON OLDER MOTHER AND HER FAMILY: POSITIVE THEMES}

\section{(181\%) Satisfaction-Positive Affect (SAT-AFF)}

Mother has positive affect or good morale, improved mental outlook, in relation to or as a result of her work; is happy or interested in, satisfied with, enjoys or loves work. Not working is associated with negative affect.

"It's been good for her. She loves it."

"She just loves it. And I've just seen her kind of blossom."

Yeah. She's in a much better mood... She's, you know, in a lot better spirits and has a lot better outlook about things. It's real easy to get depressed when you go out time after time, can't get anywhere, and then you know. Especially when you know, they don't tell you it's your age, but you know it is.

"Mentally it (work) has done her a world of good. It is great for her...She loves to work."

It's just good she's working. She's a lot happier when she's working, when she's not home all the time, so it's good for her to be working. She needs to work probably more than she does now.

She is enjoying this job a lot more than some of the others she has had through--.--. When she is working she has a lot better outlook. I can tell that she enjoys working, and she likes this job. 
"\$2.20 an hour, and she gets travel time, and mileage, and lunch. My mother's working is more for the mental therapy than for the money."

In general period, it's affected her morale. She likes to work, she likes to be able to do something for herself and when she's not working she'd kind of depressed. So, I would say she's just kind of depressed without working and feels better when she is working.

"In my mother's case it's good, it is darn good for her, because she is pretty depressed without it."

There were times when she was not working and she would get very depressed and it was very difficult to even be with her, because she was angry and snapping and nobody could do anything right, it was really difficult, and she doesn't have that moodiness now. So it's just a lot easier.

\section{(75\%) Satisfaction-Structure (SAT-STRUC)}

Mother's work provides structure, activity, something to do or someplace to go during the day, something to fill time, to be involved in, to organize day, to keep active, involved or busy, or occupy mind or self; or alternative to doing nothing.

"She is extremely miserable when she doesn't have someplace to go. She needs something to occupy her time."

"I think it's helped her a lot just to have a job, just to be keeping busy."

I think it (work) has affected her greatly because she wasn't doing much for a couple of years, just hanging around the house, not doing anything at all, basically kind of a loner. And she's got this job now, so now she is out of the house everyday. 
"Well, since she has had her work, she is extremely miserable when she doesn't have someplace to go. She needs something to occupy her time."

" It (work) keeps her going...she likes to be active."

"If she didn't have it, if she didn't have Foster Grandparents, and those little babies, she would probably be wasted away in a rocking chair someplace, and that is just not mother."

\section{(69\%) Work-Derived Financial Independence (W-IND-PAY)}

Mother's work provides economic rewards, e.g., pay or benefits (health insurance, meals). Indicates financial independence or means of survival, security, or support. Mother's periods of not working placed financial demands or stress on adult child and/or other family members.

"...and when she doesn't have any money that's unpleasant for everyone."

"That is one of the reasons she got involved with the -.-program, because of the small stipend they get. They have given her additional resources she didn't have."

"I hate to see her work just because she needs the money...But, you know, she needs the money."

"(Work) provides her a means of freeing up a little more of her income for other things other than basic necessities."

"She likes to know there's going to be money in the bank for her to pay bills." 
(56\%) Work-Derived Social/Emotional Independence (W-IND-SE)

Mother's work makes older woman less dependent on family for emotional and/or social support; increases contact with others outside the family. Family members may feel relieved or less worried about mother as a result of her working, taking a load off the family. Mother's periods of not working placed social and/or emotional demands or stress on adult child and/or other family members.

"As far as her working is concerned, it has removed a lot of the emotional dependency that she had developed on me and helped her become emotionally independent again."

Well, I have always worked in my own home, and I take one day a week as a rule off, unless there is an emergency, to do my shopping and get my hair done, whatever I want to do....So when what you have to do demands more than one day, and you can't put everything into that one day, but it sounds terrible. When she wasn't working, she wanted lunch more often during the week. I'm home, aren't I available to do these things? So she could never quite understand it doesn't work that way. So this gives me more freedom. I can kind of channel our lunches and shopping sprees.

She has become a lot more independent. Not quite so having to depend on dad or the family, or the brothers and sisters. She is really independent in fact, that even though she only lip reads, she doesn't hear that well, she still goes out there and does all those things and is pretty good at it.

"She is learning, by herself, (that) she doesn't need to have somebody else make her happy, she can do it on her own, and I think this job has had a lot to do with it."

This has been a very positive thing for her...for the most part it has put her back in an extremely functional mode and relieved 
me of a great deal of emotional responsibility, and physical burden as well. Because there were a lot of things at that time she was asking me to do for her that she really was quite capable of doing, but emotionally didn't see herself being able to do it.

\section{(41\%) Improved Communication (COMM)}

Mothers work improves communication with adult child and/or other family members; provides topics of conversation and a basis for shared understanding.

"When I see her and visit with her, which is really often, probably about a quarter of our conversation relates to her job."

"...of course, it's a point of conversation...She brings all those things home and tells us what is going on and her special favors for kids, and so forth."

"She will bring up some interesting things, I don't ask her that much, I guess that she usually just talks to me. And then once we get talking, I will ask her things about it (work)."

"Let's see. We talk very much about her work...we talk a lot....so, if anything, it is stimulating conversations."

"I feel comfortable talking to her about her work and my work...we have that in common."

"Probably.....It gives us another topic to talk about."

"Yeah, Yeah. Just because she will be, you know, just a little bit more bouncy and talkative. You know, it is a new thing we can talk about. Gives you more chance to (talk)."

"Always. She always talks to me about her job, and the things that bother her. She always talks to me about anything that 
bothers her, you know, (that's) part of being friends with her."

"She talks a lot about her work, so we listen to that...we interact with her."

"Gosh, I guess we do that a lot. We talk to each other about things...our jobs, just on life in general. We talk. We have a pretty good relationship."

\section{(38\%) Improved Relations (IMP-REL)}

Mother's work improves her relationship with the adult child and/or other family members.

"Oh, she's just...easier to get along with. Yeah. The frustration, the tension, is not as heavy as it used to be...It makes it easier to deal with her."

It is easier for me to want to be with her, do things with her, when I don't feel sorry for her...it would be harder for me to honestly want to do things with her and enjoy it, so I think the work...is very good for our relationship.

With my wife, the other responsibilities have helped their relationship...She used to save up everything and every concern and hit my wife with it when she came up. Now they are so close that these types of things just don't happen. So perhaps, if anything, if anything it has helped relationships, not so much with me, but maybe more with my wife. And it helps my mother understand the kids, because she can, she sees these kids, and I think that helps her with my kids too

\section{(38\%) Satisfaction-Purpose (SAT-PUR)}

Mother's work provides a sense of purpose, feelings of productivity, usefulness, sense of doing something worthwhile or of value; allows mother to overcome self absorption or forget about own 
problems. Not working is associated with feelings of uselessness and/or preoccupation with one's own problems.

"Well, from talking to her the impression I get is that she feels that she has something that is worthwhile doing and that gives her a purpose."

"It gives her more of a sense of worth and value. She gets a lot out of that."

"She's busy. She doesn't have time to sit and think about herself and call and worry."

"It's good for her. Like I said, it gets her mind off her problems she could have. It's a positive thing for her to do."

"It takes her mind off the problems she might have... Rather than sitting at home thinking about what certain problems might be bugging her."

\section{(34\%) Satisfaction-Purpose-Serve (SAT-PUR-SE)}

Mother's work provides a sense of purpose specifically in being able to serve clients, serve society, doing work that is helpful, socially meaningful or useful to others.

I don't think working at ....- is particularly something that she looks on as pleasurable, I think it is something which fulfills a need; you know, satisfaction from somebody needing her.

"She feels useful, it really means a lot to her that those kids like her and the people comment on how good she is." 
"It gives her, you know, something, somebody to care about, somebody to take care of, and she really cares about those kids that she takes care of."

"The point was simply for her to find some activity she thought...that would...provide some value to someone else, whether it was paid or not."

My understanding of what my mother does is she provides...a service of love and kindness to the little ones, and she helps out wherever the instructors in the center think that she is necessary. And she really gives out a lot of love, and that is what gives her purpose there, is to love them babies.

"She's a person who has to be looking out for someone...she has to feel needed."

Senior citizens and children in the society...they have a lot in common, they are good for each other...she helped some little kid today. I am sure the little kid goes back and talks about grandma ---..

\section{(31\%) Other Esteem (O-EST).}

Adult child and/or other family members feel positive, glad, or happy about, proud, admiring, or appreciative of mother's working.

"It has made me feel real proud of her. Everybody knows her, the ones that have seen her on T.V. and that say, 'I seen your mom on T.V.' Makes me feel really proud."

"My brother and I have told her that we admire her for wanting to work as long and and as much as she can."

"This ---- program has done her a tremendous amount of good...I think it's a marvelous thing." 
"I think that it is great that she is there...I think that it's really good for her, I am glad that she has got it."

"I am so glad, so proud of mother...

\section{(31\%) Satisfaction-Social-General (SAT-SOC-G)}

Mother's work provides social contact generally, the experience of being around people in a social environment. Recognition of the importance of the generalized other (i.e. "people") in the work place.

"She really likes...working with people."

"But I think mostly, some of it might have been ...the need to be around other people."

"She really needs to be out there doing something with people, and I can see that's a good thing."

"I would say it was the best thing for her to be out there working. I think she needs to get out with people."

\section{(28\%) Satisfaction-Self-Esteem (SAT-EST).}

Mother's work provides a sense of self-esteem, confidence, feelings of competence or ability; not working is associated with lowered self-esteem.

"She feels better about herself."

Her working has built her self-esteem up, her self-worth up, I don't have to keep encouraging her that you can do this, you don't need to be married, you don't have to go out and find a new husband. 
"As far as working is concerned, as far as she is concerned,... it's helped her in that it's just restored a great deal of her selfesteem and put her back in a more functional mode."

"She feels good about herself when she works."

"I think it probably gives her more self-confidence that she has a job."

\section{(16\%) Work-Derived Physical Independence (W-IND-PHY)}

Mother's work promotes or indicates physical health of older woman, indicates youthfulness or being younger than years.

"I think physically she is not impaired from doing it...and she needs that activity, she needs to keep moving, or she is going to be a vegetable."

The more you use your body the longer your body, in reality, is going to last. And so I am very pleased that she is out walking, I am pleased that she is climbing those steps to get on the bus.

"It's kind of nice to see your mom hanging in there and being a young person. I hope I am a lot like her when I get older."

She is just constantly going at one thing or another, as old as she is, she's in her 60's which really isn't that old, but she is a remarkable thing. I hope that I am as spry when I get up there.

\section{(13\%) General Work-Derived Independence (W-IND)}

Mother's work provides independence and/or security, nature unspecified.

"She likes her independence, and this has given it back to her." 
"I think she feels independent. That (work) helps her feelings of independence."

\section{(13\%) Time Positive (TIME-POS)}

Mother's work enhances or improves time spent, increases quality time with adult child and/or other family members.

"... so it's probably more quality time."

"I probably see her more now that she's working, because we're working in the same place."

Actually she spends more time with me now because she only works five hours a day, and our hours are pretty much the same as her working. I think right now, at this point in time, we are spending more time together.

\section{(9\%) Satisfaction-Purpose-Challenge (SAT-PUR-CH)}

Work provides a sense of purpose by providing activity that is inherently interesting or challenging. Meaning or value of work tied to the cognitive aspects of work, i.e. taking on responsibility, gaining new knowledge or skills.

"I think that she is more stimulated...because she is more challenged with her job"

"She is learning computer, which is something in demand..."

"I think it has helped her. I think it has given her responsibility..."

"Plus the responsibility. I think that it is good for her. I think that it has helped her." 
EFFECTS OF WORK ON OLDER MOTHER AND HER FAMILY:

NEGATIVE THEMES

\section{(44\%) Work-Derived Physical/Emotional Stress (W-STRES)}

Mother's work is tiring, creates health or other problems, physical or emotional stress; working is hard on mother; mother dislikes working; adult child is concerned or worried about mother because of working.

"I think overall working...the more she works, the more tired she is."

I think she would choose not to work if she had the option...I think she's spent a lot of years not working, and even though there's a need for her to go out and work, if she had the option, I think she would choose not to work.

She works part time, and she's so tired, you know, she'll stay home more. And, I think part of it has to do with all these years, that was a little bit less stressful, like raising children is like that...It still doesn't come natural to her to think of being a career woman.

She seems to get moved around from program to program, someone will train her and then she gets moved and...How are you going to feel very positive about that? She's probably thinking I can't wait until I get social security or something, and I don't have to worry about that.

And this year she's not been happy, and I think it's reflected in her health, it's a real stressful situation. I would hope if she continues in the program she would have another placement next year. A new one.

"She has had several health concerns this year. Those are partially working related, partially age-related, partially the effect that she is working with little kids." 
Her health changed a lot...because of the work. Because she wouldn't have caught the damn cold if she hadn't been out walking 20 blocks in the cold and wind, stuff like that. She wouldn't have sprained her arm falling down, sprained her arm, sprained her ankle or anything, if she hadn't been walking back and forth to work.

It has put a little bit more of a burden on us, I think, because of the fact that it causes her health to be a little bit more fragile. She's spent a lot of time in and out of the hospital in the last three years.

\section{(41\%) Work-Derived Visits-Decrease (W-VIS-DEC)}

Mother's work interferes with or decreases visits, getting together, or phone conversations with adult child or other family members; mother's work makes it more difficult to coordinate or schedule visits or phone calls with adult child or other family members.

"I think we were spending more time together when she wasn't working at all."

"Other than the fact that we have to call back and forth to each other and figure out times, times when she is going to be home, or times when there are appointments she has to do..."

"Yeah, she's busy, you know, just started working back steady, not a whole lot of time, but I try to see her on Sundays, I go over there."

She doesn't see my sister a lot, my sister who lives in Vancouver...When my mom wasn't working she spent more time with my sister's family...so I think (with) her working schedule, she doesn't go over there as much. 
It hasn't affected it that much other than, as I had mentioned earlier, during summer times, I occasionally might have a little time off, I suppose. We might have done something more together, perhaps taken a couple of day trips to the beach together.

I used to see her once a week, once a week. And another thing, too, when she started this job like sometimes the hours just don't fit in. My husband is usually off when I'm off, and usually, you know, I'm busy, you know, with him, and his family and everything. And then like I could go see my mother in the afternoons, but then she's working until 5, and then after she gets off my husband is home. So that too, you know, kind of makes a conflict.

The majority of them no, other than she might be gone when they can come. But they have to fit their schedules to hers, she has fitted hers so many years to theirs. So, it's about time there was some reciprocation.

"Now that she is working...so she is not always home whenever we go over there."

"She just don't have the time to go over and see them, and they kind of feel that, well, she won't go over to see us so we won't go over and see her."

"Oh, it hasn't really affected me except that she's not home all the time when I go there. When I go home for lunch some time in the day time, she is not there."

"I think a little bit. I think we were spending more time when she wasn't working at all, a little more time."

My times that I could spend with her now is, for the most part, time that she is working...so when I do have time, the morning hours, are when she is busy, and that makes it doubly difficult. 
(28\%) Work-Derived Time Decrease (W-TIME-DEC)

Mother's work decreases the amount of time spent with adult child and/or other family members; mother's work together with her other responsibilities fills her time or leaves her time for little else.

"I think as her hours increase, there's a little less time." "Well, she's not available as often as when she wasn't working."

"Well, it's kind of hard to say,...you know, I guess maybe it's made us more distant..."

"Well, how should I put this? As far as being close, I don't think that we are close...she now works and so it has drawn us apart."

"She doesn't have the free time she did when she wasn't working."

The only family she has is her mother and father, she is an only...They didn't like it because she wasn't available to them...They don't, I don't think they make her feel guilty for it, but they do let her know that they need more of her time.

\section{(16\%) Work-Derived Child care Decrease (W-CC-DEC)}

Mother's work decreases her availability for care of, or time spent with, grand-/greatgrand children.

"Grandkids. There's a flock of grandkids. Some of them used to come and stay with her, two or three days with her, and that's more limited now, of course, than it was." 
"The fact that she is working, she is not as able to stay and help me with babysitting or something like that."

"When mom wasn't working..she would go over and watch the kids when my sister was doing things, so her working schedule, she doesn't go over there as much."

\section{(10\%) Adult Child's Work (AC-WK)}

Adult child works, is busy, has limited time; adult child's work or being busy interferes with, decreases family visits or time spent together.

"It's always been real hard pressure-wise because of my job...I have to be there all the time."

Maybe my job has, my goals and stuff, have affected (the relationship) because I've been more busier...I just haven't given the time I normally would because I haven't been available.

\section{EFFECTS OF WORK ON OLDER MOTHER AND HER FAMILY: NEUTRAL THEME}

\section{Always Worked (AW)}

Mother has always worked.

"She's always worked, I'm 38 years old, and for thirty-eight years she's always worked.it's always remained the same..."

"She has worked all of her life. So all the things that we do together...are basically the same." 
"I don't think it (work) has really affected us, like I said, she has always worked all of her life."

\section{THEMES IN CONTEXT}

The foregoing presentation described the individual themes as they were coded by the two coders. Presenting the separate responses in this way, however, fails to do justice to the richness of the interview material, since typically response units contained multiple themes. The following section presents some illustrative examples of these multi-thematic response units.

A 43 year old son answered the question "How do you think your mother's working/volunteering has affected her relationship in general with you?" in the following way:

I think she feels independent, that (work) helps her feelings of independence. She does get somewhat of an income from it and so forth. But it gives her more of a sense of worth and value, she gets a lot out of that, and so she does not feel so dependent on us for a lot of the things she gets from the program. (Coded as W-Ind, W-Ind-Pay, Sat-Pur, Sat-Est, and W-Ind-SE)

In answer to the same question, a 36 year old daughter noted:

Well, I'd say it was easier for both of us, because she is the type of person...Before she started working, you know, she's like two different people. And it's so obvious and so separate about her, and she doesn't see it at all. But a good example is if you ever ask her logically, she will tell you I'm married and I need to put time in with my kids and my husband, and like that, you know, and she would be totally supportive of that. But emotionally it's like she wants me with her. She wants me to entertain her, to be with her, and kind of forget the others. But that's all the emotional thing, and so there...oh, she would 
put so much pressure on me before she started working.

Because her whole thing after the stroke, you know, how they can tend to be. She was real, almost like wimpy, and would like whine and complain, where it wasn't her style at all. And it was just always, 'I just can't be up there alone. I'm alone all the time and I've always been with people.' And, you know, 'You never do anything with me' and this and that, you know, it was just like can't you come? Like she would be there 20 times a day, 'Can't you play some games with me?', you know, stuff like that. Gosh, it was so hard on me. And when she got her job, that just took a lot more of her day up, and when she's home she's got stuff to do on her own, and it's a much more normal lifestyle for her, so it really eases up on me. And I'm sure it makes her feel better, she's not frustrated and lonely, so, you know, she gets a lot of outlet helping other people, and having people appreciate her. (Coded as Imp-Rel, Wind-SE, SatStruc, Sat-Aff, Sat-Pur-SE, and Sat-Soc-G)

\section{And from a 37 year old son :}

I think it is good because it gives her other areas to focus on. She, you know, I guess mothers tend to worry about their sons, and I don't hear that. My wife hears that type of thing. And I think my wife hears less of that with my mothers work, her other responsibilities, her other concerns, other responsibilities to worry about. So I think that is good for her. (Coded as: Sat-Pur, and W-Ind-SE)

And finally from a 41 year old daughter:

I have more respect for her as a person because she is more independent. She is more assertive than she was before and more interesting. And also because she doesn't.......it is easier for me to want to be with her, do things with her, when I don't feel sorry for her. If she was just sitting around home saying 'poor me, I am alone, and depressed, and worried' and all those things, it would be harder for me to honestly want to do things with her and enjoy it. So, I think the work is very good for her and for our relationship. (Coded as O-Est, Sat-Est, W-Ind-SE, Sat-Pur, and Imp-Rel) 
In answer to the question "How do you think your mother's work has affected her?", a 41 year old daughter stated:

I think it has affected her two-fold. One is that in some ways it is hard on her. She actually economically needs to work because my father and she are separated, and my father gives her monthly alimony but not good enough for her to live on, so it is necessary for her to work part time, And sometimes it is hard on her because she has arthritis pretty badly and sometimes it is difficult for her to just hang in there and keep working when she doesn't feel that well. She works on, I think, half time, 20 hours a week, and so at times when she is not feeling well I feel a little bit badly because it's hard on her. But then, the flip side of it, it is also very good for her emotionally. It causes her to be forced to get out and do something productive. She feels good about herself for earning a large part of her own money and also because of the social contacts. She really enjoys meeting people. And when I see her and visit with her, which is really often, probably about a quarter of our conversations are related to her job. She is very interested. (Coded as W-Stres, W-Ind-Pay, Sat-Struc, Sat-Pur Sat-Est, Sat-Soc-G, Comm, and Sat-Aff)

\section{A 33 year old son responded to the same question:}

They (other adult children) like it too, because to put it bluntly, and not to be impersonal about it, she needs an income. And all three of us, if we were to get together, we could support her, but really, who wants to do that? Let's just put it plainly, who wants to support someone when we all feel that she still has 4 or 5 good working years left? And then she will have social security. And when the time comes we would be happy to help, but when she can go out and work, working will keep her mind busy. It will actually keep her younger than sitting here would. In my opinion she needs to be busy. She likes to be around people. If she believes in something she is a heck of a salesman. If she believes in it, it has to be of a true benefit to someone to sell it. But, if she believes in it, you can't find a better salesman than her. But it is great. It is great for all 
three of us. Her working is good for all of us. (Coded as O-Est, W-Ind-Pay, Sat-Pur, W-Ind-Phy, Sat-Struc, and Sat-Soc-G)

\section{A 33 year old daughter responded:}

I think that it's probably, you know, filled her life with something to do. You know, she enjoys it, she talks about it a lot. And I think it, you know, I don't know how to say it, I think it's that she has a purpose in life; to go out and help these people. You know, because me and my sister don't see her that much and she needs something to do on her own." (Coded as Sat-Struc, Sat-Aff, Comm, and Sat-Pur-SE)

\section{A 37 year old son commented:}

She talks about the students. I think some of the students there, I don't know their backgrounds, but I think a lot of them like affection and attention. And I think the students like having the foster grandmother, and I think she can feel that from them because periodically they make her things. On her birthday they all make her cards, and I think that warmth is communicated, and $I$ think it is a big reward. Plus the responsibility, I think that is good for her. I think she feels better and healthier. (Coded as Comm, Sat-Pur-SE, Sat-Pur-CH, Sat-Aff, and W-Ind-Phy)

And a 27 year old son remarked:

I think that it has affected her greatly, because she wasn't doing much for a couple of years, just hanging around the house, not doing anything at all, basically kind of a loner. And she got this job now, so now she is out of the house everyday and she is interested in it. She comes home, she has things to talk about she didn't have before. 
QUANTITATIVE ANALYSES

\section{Chi-square Analyses}

A series of Chi-square analyses was conducted to examine the presence/absence of the 21 themes in each interview as a function of gender of the adult child. Of the 21 analyses performed, only one was significant and only two were marginally significant, about the percentage one would expect by chance alone. However, because of the exploratory nature of this study, these results are reported here. Adult daughters were significantly more likely than sons to mention that their mother's work decreased the amount of time they spent together, $\underline{x}^{2}(1, n=32)=5.34, \underline{p}<.02$. Daughters were also marginally more likely to report that their mother's work decreased the number of visits and phone calls to each other, $\underline{x}^{2}(1, n=32)=3.24, \underline{p}<.07$. On the other hand, sons were marginally more likely than daughters to mention the Satisfaction-Positive-Affect theme indicating that their mother liked her work, $\underline{x}^{2}(1, \mathrm{n}=32)=3.28, \underline{\mathrm{p}}<.07$.

The presence/absence of themes in each interview as a function of mother's work program, i.e., Foster Grandparent Program (FGP) or Senior Community Service Employment Program (SCSEP), was also examined. Of the 21 chi-square analyses performed, two were significant and one was marginally significant, again not much more than chance would predict. Adult children whose mothers were in the FGP Program were more likely than those whose mothers were in the SCSEP Program to mention the Communication theme, i.e., that mother's work improves communication or provides topics of 
shared understanding, $\chi^{2}(1, \mathrm{n}=332)=6.35, \mathrm{p}<.01$. Adult children whose mothers were in the SCSEP program were more likely to indicate that their mother had always worked, $\underline{x}^{2}(1, \mathrm{n}=32)=8.96, \mathrm{p}<$ .003). Finally, children whose mothers were in the FGP program were marginally more likely to mention the Satisfaction-PurposeServe theme, i.e., that mother's work provided her with a sense of purpose vis-a-vis socially meaningful service to others, $\underline{x}^{2}$ $(1, \mathrm{n}=32)=3.46, \mathrm{p}<.06$.

\section{Correlational Analyses}

A series of point bi-serial correlational analyses examining presence/absence of themes in relation to age of mother and age of adult child was also performed. (As would be expected, mother's and child's ages were significantly correlated, $\underline{I}=.71, \mathrm{p}<, 01)$. Of the 21 analyses relating mother's age to presence/absence of themes in her child's interview, only three were significant. The older the mother the more likely her child was to mention the theme SatisfactionPurpose, i.e., that mother's work provided her with a sense of purpose, feelings of productivity and usefulness, $(\underline{r}=.47, \underline{p}<.01)$. Age of the mother was also positively related to mention by the child of the Communication theme, i.e., that mother's work improves communication with adult child and/or other family members $(\underline{\mathrm{r}}=.35, \underline{\mathrm{p}}<$ $.05)$. And finally, age of mother was negatively related to the Always Worked theme $(\underline{\mathrm{r}}=.36, \underline{\mathrm{p}}<.05$.$) . That is, children with$ younger mothers were more likely then children with older mothers to indicate that their mother had always worked. 
Of the 21 analyses relating adult child's age to presence/absence of themes, only one was significant. Older children were more likely than younger children to mention the Satisfaction-Purpose theme, i.e., that mother's work provided her with a sense of purpose or feelings of productivity and usefulness $(\underline{\mathrm{r}}=.53, \mathrm{p}<.01)$. This relationship remained significant at the $p<.05$ level when Bonferroni-corrected for 21 correlations.

\section{EFFECTS OF WORK ON OLDER WOMEN IN GENERAL}

The attitudes of the sons and daughters towards the work of older women in general was also of interest in this study. As can be see in Table V, some of the same themes used to describe the effects of work on the older mother and her family were also elicited when the employment of older women in general was the focus of the questions.

A 45 year old daughter responding to the question, "In general how do you think working/volunteering is good for older women? ", replied:

Oh I definitely think so. Structured activity is good for most people, as long as they are physically able to participate. As long as people are alive, constructive interaction with other people is very important to their mental processes; to their mental, physical, and emotional well-being. I know too well that too much solitude is not good for people, for most people, there are, of course, exceptions, but I think most people need other people. And the more able they are, the more able people are to see their lives as being productive, to be contributing to the welfare of society, the more productive and 
TABLE V

NUMBER AND PERCENTAGES OF RESPONDENTS

MENTIONING EACH THEME REGARDING

OLDER WORKERS IN GENERAL

$\triangle \quad \% \quad$ POSITIVE

$12 \quad 38$ W-IND-PAY-G General Work-Derived Financial

Independence

1134 SAT-SOC-G-G Satisfaction-Social-General-

General

1134 SAT-PUR-G $\quad$ Satisfaction-Purpose-

General

722 SAT-PUR-SE-G $\underline{\text { Satisfaction-Purpose-Social/Emotional }}$ General

619 SAT-AFF-G Satisfaction-Positive-AffectGeneral

619 W-IND-PHY-G Work-Derived Physical IndependenceGeneral

516 SAT-EST-G Satisfaction-Self-Esteem-General

310 SAT-PUR-CH-G Satisfaction-Purpose-Challenge-General

13 W-IND-G Work-Derived Independence-General

N $\% \quad$ Negative

$14 \quad 44 \quad$ W-STRES-G Work-Derived Physical/Emotional Stress -General 
contributing members they are. (Coded as Sat-Struc-G, SatSoc-G, W-Ind-Phy-G, Sat-Aff-G, Sat-Pur-SE-G)

\section{A 43 year old son answered the same question:}

They benefit from having a sense of self-worth, and filling up their time. If they work, and so forth, you know, they have a real feeling of contributing to society. All the volunteer work, society benefits greatly from it. (Coded as Sat-Est-G, Sat-StrucG, and Sat-Pur-G)

Another son, 47, commented:

Well, I think everybody needs a feeling of independence, and not to be, the need to rely on somebody else. Certainly working, and in the case of working to get a paycheck, that gives them some financial benefit and independence. As far as volunteer work where there isn't any pay, at least just to get them out of the house, and allowing them to make their time more useful. And it probably allows them to forget their own problems, and keeps them busy with something else. (Coded as W-Ind-G, W-Ind-Pay-G, Sat-Struc-G, and Sat-Pur-G)

And finally, another 47 year old son commented on the question, " Do you think older workers/volunteers should get more pay or benefits for the work they do?"

Oh... I think that experience should be rewarded and wisdom should have compensation. I think we have negated a huge resource pool in not utilizing the senior citizen in this country to the extent that they should be used, and I think that would be very beneficial not only to society but to the older individuals. Studies have shown repeatedly that the more useful an individual feels the better they function in their environment and the greater their longevity, and fewer health care problems they have. And so, I see it again, as a synergistic effect: The more we take advantage of the skills and wisdom and knowledge and experience of the older individuals. Studies have shown repeatedly that the more useful an individual feels the better they function in their environment and the greater their longevity, and fewer health care problems they have. And so, I see it again, as a 
synergistic effect: The more we take advantage of the skills and wisdom and knowledge and experience of the older generation, the less it's going to cost us and society in longterm care for those individuals, and the less they are, you know, the fewer resources they will consume if they have a positive outlet for their energies. They're going to spend less time complaining or engaged in activities that absorb resources that might better be spent someplace else, so it's a better use of resources all the way around. And that's not to say some people are not going to be big resource consumers, because of age, just because they're active, but I think you get a better distribution of resources, and a better, healthier relationship for a greater portion of the population when everybody functions at the level most comfortable for them. (Coded as Sat-Pur-SE-G, W-Ind-Phy-G, and Sat-Pur-G) 


\section{CHAPTER IV}

\section{DISCUSSION}

This study examined the perceptions of adult sons and daughters concerning the effects of their mothers' later life work force participation. The perceived impact of maternal employment not only on the older mother, but on the adult child and other family members, was of primary interest.

Work was generally seen by the adult children as having many positive and salutary effects on the older woman. The theme most often mentioned was Satisfaction-Positive Affect. Over eighty percent of the respondents believed that their mother liked her work or thought that her work was associated with improved mental outlook and a sense of good morale in the older woman. Some children mentioned that their mothers had been depressed and irritable during former periods when they were not employed. The prevalence of this theme in the present data is consistent with results from other research. Riddick (1985) found that when compared with homemakers and retirees of the same cohort, labor force participation by older women had a significant effect on their perceived life satisfaction. A study by Jaslow in 1976 even went so far as to suggest that participation in the paid work force may provide psychosocial benefits that 
carry over past the time of retirement and into old age. In the present study a related but less frequently mentioned theme was Satisfaction-Self-Esteem. Almost $30 \%$ of the adult children believed that their mother's self-esteem had been enhanced as a result of her work. These data are supported by Jaslow (1976), who found that employment tended to provide older women with a source of dignity and self-esteem.

The theme mentioned second most frequently by the adult children was Satisfaction-Structure. Seventy-five percent of the respondents stated that their mother's work provided structure in that it gave her someplace to go, something to do, or some activity in which to be involved in or around which to organize her day. This structure-providing function of employment has been found repeatedly in studies of workers in general, including women in blue collar and service occupations (Walshok, 1979).

Almost $70 \%$ of the respondents mentioned the third most common theme, Work-derived Financial Independence: the financial and related benefits afforded by their mothers' working. Inspection of the responses coded by the raters as examples of this theme indicated that two different subthemes were present in the data. One subtheme referred simply to the financial benefits of work ("That is one of the reasons that she got involved in the----program, because of the small stipend they get. They have given her additional resources that she didn't have." "She actually economically needs the work...my father gives her some monthly alimony but not good enough for her to live on." "She just had her Social Security...she still 
needed the feeling of independence, a few bucks in the bank should something go wrong, so until she started working she didn't have that.") The other subtheme referred to the relational aspects of those financial benefits, i.e., their effects on the relationship between mother and child. A secondary analysis of all work-derived financial independence themes indicated that nine of the adult children (28\% of the total sample) viewed the financial benefits of their mother's work in these relational terms. These respondents often expressed a sense of relief from the pressure of their own financial obligation to their mothers as a result of the income provided via her work ("...The fact that because she has some income coming in, even though I still ask her, 'Mom, do you need any money?' she always says 'no'. But I think now when she says 'no' I can accept it a little bit more as being truthful than I could before. I think before she said it out of sheer pride, now she's saying no because she doesn't need." "I guess we just take it for granted, that we expect that she should have a job and support herself. When she has a hard time with that I suppose we get somewhat irritated." "We really expect her to do that. We would feel resentful if she was able to work and just stayed home when she felt like it and wanted us to support her.").

Several noted that this situation might change in the future. A son commented, "If she stops working I will probably have to put up more cash, or whatever, to keep things solvent." A daughter remarked, "I think down the road if she was not able to (work), if she gets in a financial situation or physically, then I would have to, I would be willing to, provide some of the other things I am not cur- 
rently providing." Herz (1988) noted that a large percentage of divorced women 55 and older depended solely on their own earnings, other sources of income, or both for support. In 1984, for example, $75 \%$ of unmarried women ages 62 to 64 and $31 \%$ of those age 65 or older who were employed depended on their earnings for at least half their total income.

Work was seen by the adult children as having other important benefits to their mothers. It was viewed (by 16\%) as evidence of her youthfulness and physical health. In addition, a major theme that emerged in one form or another was that mother's work provided her with purpose, a sense of doing something worthwhile or of value. This purpose theme was coded in several different ways. References to purpose generally or the fact that mother's work allowed her to overcome self-absorption,were coded as Satisfaction-Purpose (mentioned by $38 \%$ of the adult children). Work also gave the mothers a sense of purpose by providing an activity that was inherently interesting or challenging. This theme, coded as Satisfaction-Purpose-Challenge, was mentioned by a small percentage of the respondents (9\%). In addition, mothers' work was seen to provide a sense of purpose in that she was able to serve clients and society by doing work that was helpful, socially meaningful or useful to others. This category, coded as SatisfactionPurpose Serve, was mentioned by $34 \%$ of the adult children. Other research supports the importance to older persons of service to others. When asked what makes a useful member of one's community, the attribute mentioned most often by persons 65 and 
over in a nationwide poll was helping and serving others (L. Harris and Associates, Inc., 1975).

In addition to giving her a sense of purpose, the adult children considered their mother's work to be beneficial to her because it provided her with social contact and an opportunity to interact with other people in a social environment. Thirty-one percent of the respondents mentioned this theme, coded as Satisfaction-SocialGeneral, recognizing the benefit of their mothers' being around other people in the work place. Other research has also shown the importance, particularly to women, of social relationships in the work place (Repetti, Matthews, \& Waldron, 1989).

The preceding discussion has dealt for the most part with those themes that focused on the perceived effects of work on the mother herself. These themes have proved important in other research that has examined work effects on women, including older women. What is new about the present study is the documentation of several themes suggesting that mother's work affected the mother-child relationship.

Social-Emotional Independence, mentioned by $56 \%$ of the respondents, was the most prevalent of these relational themes. A job was seen by the adult child as important to his/her older working mother in that it provided the older woman with increased social contact and opportunities outside the family, thus attenuating her son's or daughter's need to provide her with social and emotional support. Prior to her employment the mother had often been dependent on her adult son and/or daughter and other family mem- 
bers for her primary social support. The adult children felt that work provided their mothers with an opportunity to meet new people and form new attachments and interests independent of input and influence of the child. Many of the adult sons and daughters expressed a sense of relief that the emotional burden had been shifted from them as a result of their mothers' employment.

In addition, mothers' work was seen by over $40 \%$ of the respondents as improving communication (Communication) between mother and child, by providing topics of conversation and a basis for shared understanding. In that same vein, her work was perceived as enhancing or improving the time she spent with her adult offspring (Time Positive), mentioned by $13 \%$ of the respondents.

And, as discussed earlier, income from the mothers' work force participation alleviated the need for financial assistance from her offspring (mentioned by $28 \%$ of the adult children).

Overall, $31 \%$ of the adult children mentioned that they admired or were proud of their mother for working, and $38 \%$ of the children specifically stated that their relationship with their mother had improved as a result of her employment. It must be remembered that this Improved Relationship theme was scored only if the respondent noted explicitly that the relationship between child and mother had benefited, been improved or made easier by mother's working. "Oh, she's just easier to get along with. Yeah. The frustration, the tension, is not as heavy as it used to be." "It is easier for me to want to be with her, do things with her, when I don't feel sorry for her." 
These relational themes (Social-Emotional Independence, Financial Independence-Relational, Time Positive, Communication, Other Esteem, and Improved Relationship) are among the most important findings of the study. These adult children believed that their mother's work had positive benefits not only for her, but for the mother-child relationship. The working mother's social, emotional, and financial independence may have enhanced and improved her interactions with her adult children in a direct way by providing topics of conversation, improving the time spent together, and alleviating her need for their socioemotional and financial assistance. Additionally, their mother's work was seen by the respondents as providing her with feelings of satisfaction, a sense of self-worth, purpose, and challenge, all of which may have had an indirect positive effect on her relationship with her adult children due to her improved morale and mental outlook. At the same time, these positive effects of work on mother might have changed some of the negative perceptions that her adult children held prior to her employment. Scharlach (1987) reported that middle-aged daughters experienced less 'role strain' and a better quality of relationship when older mothers had a higher sense of psychological well-being. Despite the preponderance of positive and beneficial effects thought to derive from maternal employment, the respondents mentioned negative effects as well. In particular, forty-four percent of the adult sons and daughters noted that their mother's work was hard on her, creating Physical/Emotional Stress. 
It was not anticipated that this theme would be mentioned so often, and therefore a more refined code was not initially used. To remedy this, a secondary analysis of these data was performed. It was found that roughly one-third of the respondents $(n=10)$ expressed concern over the physical demands of their mother's job. A son stated, "When she is working she doesn't have the energy she does in the evenings otherwise." A daughter added, "She's what you'd consider clerical, does a lot of typing, answering the phone. Works four hours a day... seems to be overburdened sometimes. When I talk to her she's very tired." Another continued, "Well, I don't like to see her as tired as she is. Because she has a tendency to overdo, rather than saying 'I'll do whatever tomorrow', she has to do it today. And I think because of the way she is, the way her personality is, she puts a lot of pressure on herself and makes herself tired." And finally a son noted, "I think it has affected her health. Her health is bad and has gotten gradually worse in the last five years...I think sometimes the work puts a lot of pressure on her health-wise."

In addition to the physical stress involved, some adult sons and daughters $(n=8)$ expressed concern over their mothers' work-related emotional stress. The respondents described their mothers' anxiety over the uncertainty of her future, as well as her lack of security and benefits. "I think that she feels a bit uncertain that she doesn't have any benefits and she's not really sure about the future." "I don't think she should be doing what she's doing because she has no ben- 
efits...It's not a real job and she has lots of misgivings about that because this isn't going to hold her for very long."

One of the adult children was aware of work-related stresses that involved problems with the mother's employment program or personality clashes on the worksite. She noted, "It made her frustrated with the...program because they didn't hear her level of concern...there was definitely some communication that could have taken place that didn't." She added, "Well, in some respects it's been very positive for her, and in some respects it's been very frustrating for her. My mother has very strong opinions about how things should be done, and she's had some conflicts this year. Sometimes it's been extreme and other times a lot more mild, but she'd had some disagreements with the teacher that she works with."

The possibility that the older working mother would be less available to provide instrumental support to her child or to other family members due to her work obligations as a result of her employment was also of interest in this study. Although it was anticipated that the adult children might report a decrease in their mothers' availability this did not prove to be the case. Only five of the adult children (16\%) mentioned that their mothers' work had decreased her availability for providing child care to grandchildren and great grandchildren. No adult child mentioned specifically that their mother's work had decreased her availability to provide instrumental help other than child care to family members, although that theme had been identified on the basis of inspection of the interviews with the mothers. It is quite likely that these older 
women were socialized to "be there" for their families under any circumstances, and therefore were reluctant to shirk family responsibility in spite of the increased demands on their time due to their employment. Or in the case of child care, perhaps they were not providing a substantial amount of care to begin with due to the advanced age of their grandchildren, or had not set a precedent of being available to provide child care in the first place.

Although few adult children spoke of diminished instrumental help from their mother due to her employment, nine $(28 \%)$ of the respondents felt that their mothers' work and corresponding lack of free time had decreased the amount of time she spent with them. In addition, several $(41 \%)$ felt that her work coupled with other obligations had interfered with family get-togethers, visits and phone calls. These adult children expressed a sense of frustration in trying to plan time together when dealing with the scheduling constraints their mothers' work imposed. Overall, half of the respondents mentioned that their mother's work had affected either the amount of time spent or number of visits/phone calls made between mother and child. A few commented that this state of affairs had had a negative impact on their relationship, inducing feelings of alienation and emotional distance: "I guess it's (mother's work) made us more distant." "She works now and so it has drawn us apart." In retrospect, these remarks should have been classified under a separate thematic code to indicate that not only was the mother and adult child's time together decreased as a result of the mother's work, but their relationship itself had suffered. Perhaps a code 
entitled Time Negative would have adequately described the above statements.

Although the the large number of chi-square and correlational analyses performed on the data from this study suggests caution in interpreting the results, some interesting patterns did occur. The chisquare analyses showed that adult daughters were significantly more likely than sons to mention that their mother's work decreased the amount of time that they spent together. They were also marginally more likely to report that their mother's work decreased the number of visits and phone calls between them. That time/visits with daughters would be more likely than time/visits with sons to be impacted by the demands of the older woman's work force participation and resulting lack of free time is perhaps not surprising. Visits, phone calls, and time spent together in general are considered by social gerontologists to be forms of affective/emotional support, an aspect of help that may be more likely to be performed by daughters than sons (e.g., Robinson \& Thurner, 1979). Daughters may be more likely than sons to mention the time/visits lost as a result of mother's work if daughters were providing more of this support in the first place.

Chi-square analyses comparing presence/absence of themes as a function of mother's employment program also proved illuminating. Children of women in the Foster Grandparent Program (FGP) were more likely than those whose mothers were in the Senior Community Service Employment Program (SCSEP) to mention that work had improved communication by providing topics of 
conversation and a basis for shared understanding. One possible explanation for this finding is that women in the Foster Grandparents Program may have felt the altruistic nature of the program, and their corresponding contributions to the welfare of the children involved, gave them something worthwhile to discuss with their adult children. They may have felt that the intangible benefits of the program outweighed the sub-minimum wage they received. Or alternatively, this result may have reflected that these women felt a need to justify to their adult children their motivations for participation in the Foster Grandparent Program in light of their low monetary compensation. Children of women in the Foster Grandparent Program were also less likely to mention that their mother had always worked. Many of the FGP women may have been out of the work force for a longer period of time before beginning their present employment. Work may therefore have provided them with other interests outside of the family which in turn would have given them something new to talk about with their adult child.

The point bi-serial analyses correlating mother's and adult child's ages with presence or absence of themes were consistent in showing that the older the adult child and the older the mother, the more likely was the child were to mentioned the SatisfactionPurpose theme, i.e., that mother's work provided her with a sense of purpose, feelings of productivity and usefulness. Perhaps this finding could be attributed to the fact that older mothers (and older children) have gained an increased awareness of the importance of having a direction in life and a focus outside of oneself. They may 
have more altruistic motivations, feeling the need to give of themselves in some meaningful pursuit. It should be remembered, however, that the mothers who were older in the study were predominantly with the FGP program, a program specifically designed to bring older persons into contact with needy children. Those mothers may have been more likely than SCSEP mothers to believe (and to communicate to their child) That their work was worthwhile or of value. This line of analysis is strengthened by the finding that the older the mother the more likely her adult son or daughter was to mention that the mother's work had improved communication with her adult child and other family members. Once again, this result is likely largely due to the presence of significantly older mothers in the FGP program since children with FGP mothers were significantly more likely to mention the communication theme. The finding of a negative correlation between the age of the older woman and the mention of the theme Always Worked by her adult child is also consistent with this interpretation. In other words, this correlation is likely due not so much to age of the mother per se. but due to the fact that the oldest mothers in this study were in the FGP program.

Many insights into the feelings, environments, and personalities of the adult children were reflected in the field notes written immediately following the formal interview. The respondents, some of whom may have been intimidated by the use of a tape recorder during the structured questions, would feel more free to open up when they were no longer being recorded. 
Several commented on their childhood situations. Many of these situations were less than ideal, involving alcoholism, divorce and parental abandonment. There were often unresolved conflicts and built-up resentments that had carried over into the motheradult child relationship as a result.

Many of the mothers had been forced, due to financial necessity, to work a large percentage of their children's growing up years. As a result, several of the adult children expressed regret that their mothers had not been more available for them and that they were forced to take over many of the duties that she was unable or unwilling to do.

There seemed to be continuing dependency conflicts in relation to the mothers for some of the respondents. Comments in the field notes alluded to the fact that several had failed to establish an independent existence, either financially or emotionally, from their mother. Several still lived with their mothers and were unable to hold a steady job or contribute financially to the household.

Many of the respondents felt comfortable enough to make a fairly substantial amount of self-disclosing statements, while a few expressed wariness or feelings of uneasiness about participating in the study. The comments in the field notes sometimes expressed a sense of frustration at the lack of rapport between interviewer and respondent. One respondent even went so far as to have the interviewer sign a statement attesting to the fact that none of the material in the interview would get back to his mother. On the other hand, there were those who took self-disclosure to extremes by 
relating personal family matters that were not pertinent to the data or interview process, but were nonetheless interesting.

Establishing a foundation of trust was of utmost importance to the interview process. Due to the nature of the study, the questions and ensuing probes often dealt with areas of a sensitive and somewhat personal nature. There had to be an explicit understanding on the part of the participants that what they related would be held in strictest confidence and that anonymity would be assured during the interviewing process as well as in the final presentation of the data for publication. (The interviews were identified and catalogued solely by means of an assigned interview code number.)

\section{LIMITATIONS OF THIS STUDY}

The fact that the sample was not generated by random selection, but rather chosen from those older working mothers who volunteered to participate was a major limitation of the study. The sample size was small, primarily Caucasian, and solely from lower socio-economic status, thus limiting the generalizability of the findings to other populations. In addition, our sample of sons was atypical in that 4 out of 16 participants, $25 \%$ of the respondents, were homosexual. There was also a confound of mother's age with type of program due to the differing age requirements and philosophies of the two programs involved.

Another area of concern was the possibility of problems with internal validity. Some of the adult children who were interviewed 
did not meet the criterion of being the child with whom their older working mother had the most contact. This was due in part to the fact the two of the favored children refused to be interviewed when contacted and one of the mothers refused to have the child with whom she had the most contact be interviewed. There was also seemed to be tendency on the part of the older women involved to regard their son's time as being more valuable, or less available, than that of their daughters. This may have therefore decreased the likelihood that they would name sons as possible participants regardless of the amount of contact.

More detailed employment histories for each of the older women participants with the dates that the various positions were held would have been very useful. At the inception of the study detailed work histories were requested as part of an initial recruitment procedure through the mail. When this method of recruitment proved unsatisfactory due to low response rate this initial intake sheet was revamped, excluding the detailed work history, in order to expedite the recruitment process at the quarterly meetings of the participating agencies. The question, "Can you tell me what you've done in terms of paid employment?", was included in the interview format, but did not specify dates or an ordered chronology of positions held.

Some refinement of the current coding scheme would be beneficial and of interest. For example, the two codes Work-VisitsDecrease and Work-Time-Decrease were both listed as "negative" effects of mother's work. Yet many respondents simply noted that 
their mother's employment had affected the amount of time spent or number of visits made, without adding an evaluative comment suggesting their dislike of the situation. Differentiation of evaluative versus non-evaluative responses would be helpful. Or, using the present data, certain combinations of codes within individual interviews could be sought out. For example, those interviews where both Improved Relations (or Time Positive) and Work-VisitsDecrease (or Work-Time-Decrease) appeared could be isolated. The presence of both themes in the same interview could indicate that the respondents. Work-Visits-Decrease and Work-Time-Decreases was not a negative situation.

It would have been ideal to have found women that had had some break in employment prior to their participation in this study. How long these individuals were out of the work force could have been analyzed as a variable. A criterion for the length of time out of the work force could have been set that was long enough for some patterns to be established. Certain variables could have been isolated (e.g., the amount of time the older women were out of work prior to their employment, or a comparison of women of one age group with varying increments of unemployment prior to their reentry into the work force). This stipulation would have resulted in a difficult recruitment process although an agency such as displaced homemakers might have been a good possibility to consider for participants. Although realistically speaking, setting a strict criterion for an extended period of unemployment prior to to re-entry into the 
work force may have made recruitment of subjects difficult if not impossible.

\section{AREAS FOR FUTURE RESEARCH}

The findings of this study in conjunction with the larger comprehensive study mentioned earlier present the possibility for future research in several areas. The first area relates to a part of the interview material dealing with patterns of helping behavior and help conceptions. Research on the patterns of aid and reciprocity within the family and how these helping behaviors are affected as a result of maternal employment would be of interest.

A second area relates to the nature of the affective relationship between mother and child. Analysis of these results, as well as their relationship with help patterns and work/family effects, would be of import.

Finally a study on intergenerational relations in the work place, how the presence of an older woman in the work evironment affects the patterns of aid and reciprocity with her younger women coworkers in their 20's and 30's, is currently under investigation.

It would also be of interest to examine the ramifications of employment in older mothers in a larger sample. To achieve this end, multicentered studies with other university settings involved in data collection would increases the generalizability of the findings.

In summary, this study examined the effects of maternal employment as perceived by a sample of adult sons and daughters of 
employed older mothers. Both effects on the mother herself, and on the mother-child relationship, were reported. Further research might examine these perceived effects on a larger, more representative sample of older working mothers, involved not only in social service positions but other types of employment. Since the women who participated in this study were poverty-level persons employed through governmentally subsidized programs, it might also be of interest to examine the ramifications of maternal work force participation in women from more varied socioeconomic backgrounds. 


\section{REFERENCES}

ACTION. (1984). Impact evaluation of the Foster Grandparent Program on the foster grandparents: Final Report. Washington, D. C.: Litigation Support Services.

Brody, E. M. (1985). Parent care as a normative family stress. The Gerontologist, 25(1), 19 - 29.

Brody, E. M., Johnsen, P. T., Fulcomer, M. C. \& Lang, A. M. (1985).

Women's changing roles and help to elderly parents: Attitudes of three generations of women. In B. C. Miller \& D. H. Olson (Eds.), Family studies review book yearbook: Vol. 3 (pp. 424 434). Beverly Hills: Sage.

Cicirelli, V. G. (1983). Adult children and their elderly parents. In T. H. Brubaker (Ed.), Family relations in later life (pp. 31 - 64).

Beverly Hills: Sage.

Coleman, L. M. \& Antonucci, T. C. (1985). Impact of work on women at midlife. In B. C. Miller \& D. H. Olson (Eds.), Family studies review yearbook: Vol 3 (pp. 435-439). Beverly Hills: Sage.

Deutermann, W. V. \& Brown, S. C. (June, 1987). Voluntary part-time workers: A growing part of the labor force. Monthly Labor Review, $5-10$.

Fleisher, D. (1981). Alternative work options for older workers:

Part IV - policy implications. Aging and Work, 4(3), 153 -160.

Herz, D. E. (September, 1988). Employment characteristics of older women. Monthly Labor Review, 3 - 12.

Jaslow, P. (1976). Employment, retirement, and morale among older women. Journal of Gerontology. 31(2), 212-218. 
Kuypers, J. A. \& Bengston, V. L. (1984). Perspectives on the older family. In H. W. Quinn \& G. A. Hughston (Eds.), Independent aging: Family and social systems perspectives (pp. 2 - 19). Rockville, MD: Aspen.

L. Harris, \& Associates, Inc. The myth and reality of aging in America. Washington, D. C.: The National Council on Aging, 1975.

Mancini, J. A. (1984). Leisure lifestyles on family dynamics in old age. In H. W. Quinn \& G. A. Hughston (Eds.), Independent aging: Family and social systems perspectives (pp. 265 - 384). Rockville, MD: Aspen.

Mancini, J. A. (1984)/ Research on family life in old age: Exploring the frontiers. In W. H. Quinn \& G. A. Hughston (Eds.), Independent aging: Family and social systems perspectives (pp. 265 - 284). Rockville, MD: Aspen.

Matthews, S. H. (1979). The Social World of Old Women: Management of Self Identity. Beverly Hills: Sage.

McConnell, S. R. (1980). Alternative work patterns for an aging work force. In P. K. Ragan (Ed.), Work and retirement policy issues (pp. 68 - 86). Los Angeles: University of Southern California Press.

Morrison, M. (May, 1983). The aging of the U. S. population: Human resource implications. Monthly Labor Review, $13-19$.

Nieva, V. F. (1985). Work and family linkages. In L. Larwood, A. H. Stromberg \& B. A. Gutek (Eds.), Women and work: An annual review (Vol. 1) (pp. 162 - 190). Beverly Hills: Sage.

Payne, B. \& Bull, C. N. (1985). The older volunteer: The case for interdependence. In W. A. Patterson \& J. Quadango (Eds.), Social bonds in later life (pp. 251 - 272). Beverly Hills: Sage. 
Quinn, W. H. (1984). Automony, interdependence, and developmental delay in older generations of the family. In W. H. Quinn \& G. A. Hughston (Eds.), Independent aging: Family and social systems perspectives (pp. 21 - 32). Rockville, MD: Aspen.

Repetti, R. L., Matthews, K. A. \& Waldron, I. (November, 1989). Employment and women's health. American Psychologist. 44(11), 1394-1401.

Riddick, C. C. (1985). Life satisfaction of older female homemakers, retirees, and workers. Research on Aging, Z(3), 383 - 392.

Robinson, B. \& Thurner, M. (1979). Taking care of aged parents: A family cycle transition. The Gerontologist, 19, 586 - 593.

Shanas, E. (1982). Social myth as hypothesis: The case of the family relations of old people. In K. W. Schaie \& J. Geiwitz (Eds.), Readings in adult development and aging (pp. 65 - 73). Boston: Little, Brown.

Soldo, B. J. \& Agree, E. M., (September, 1988). America's elderly. Population Bulletin. 43(3), 23 - 30 .

Stewart, C. B. \& Smith, C. L. (1983). Prosocial behavior for and by older persons. In D. L. Bridgemen (Ed.), The nature of prosocial development: Interdiscipline theories and strategies (pp. 309 340). New York: Academic Press.

Stueve, A. (1985). The elderly as network members. In B. C. Miller \& D. H. Olson, (Eds.), Family studies review yearbook: Vol. 3 (pp. 377 - 405). Beverly Hills: Sage.

Troll, L. E. (1985). Early and Middle Adulthood (2nd ed.) (pp. 159 191). Monterey, CA: Brooks/Cole.

Usher, C. E. (1981). Alternative work options for older workers: Part 1 - employee's interest. Aging and work, 4(2), $74-80$.

Walshok, M. L. (1979). Occupational values and family roles: Women in blue collar and service occupations. In K.W. Feinstein (Ed.), Working Women and Families (pp. 63-83). Beverly Hills: Sage. 
APPENDIX A

ADULT CHILD INTERVIEW FORM 


\section{APPENDIX A}

\section{ADULT CHILD INTERVIEW FORM}

\section{A. Family Structure and Affective Relationships}

Could you tell me about your immediate family (your own family)? Could you tell me about the family you grew up in? (e.g., number of siblings, family configuration, location of siblings, etc.)

What is your understanding of what your mother does at ...... (name of organization)?

How do you think your mother's working/volunteering has affected her?

How would you describe your relationship with your mother now, at this point in your life?

How often do you see or talk with your mother? (PROBE re both visits and phone contacts. Get estimate of number of both per week, i.e., How often would that be per week?)

Who tends to initiate the visits or phone calls?

What kinds of things, if any, do you feel comfortable talking with your mother about? (PROBE for shifts over time, or as a function of older mother working.)

In what ways are you like your mother? In what ways are you unlike your mother?

In what ways do you think your relationship with your mother is similar to, or different from other people your age (i.e., What have you noticed about your relationship with your mother that seems similar to other people your age)? 
How do you imagine your relationship with your mother might change as she gets older? (If emphasis on the theme of independence, PROBE: You see your mother now as independent, and the two of you are leading relatively separate lives. What do you imagine it would be like for the two of you if she had a greater need for you in the future?)

\section{B. Patterns of Aid and Reciprocity}

Are there ways that you help your mother or she helps you?

I have a list of different types of help that family members sometimes provide for each other. I'm going to ask you which of these kinds of help, if any, you provide to your mother these days. Some time these things don't come immediately to mind, so please take your time.

* HELP LIST 1

Homemaking

Are there situations where you help your mother with homemaking activities such as shopping, cleaning, or preparing meals?

Maintenance

Are there situations where you help your mother with yard work or by doing household repairs?

Income

Are there situations where you help your mother by giving her food or goods needed to live on, or money?

Personal Care

Are there situations where you help your mother with personal care such as dressing or grooming?

Home Health Care

Are there situations where you help your mother when she is ill? 
Transportation

Do you help your mother with transportation, such as providing a means of getting to work, or visiting her friends, or taking her shopping or to church or to doctor's appointments?

Social and Recreational Activities

Are there situations where you help your mother with entertaining at home, or getting out for fun, such as accompanying her to special events or meetings?

Employment

Do you help your mother with employment, such as finding a job or a market for goods or services?

\section{Spiritual}

Do you help your mother with spiritual or religious activities?

Bureaucratic Mediation

Are there situations where you help your mother in dealing with government agencies or businesses, such as making phone calls or filling out forms?

Reading Materials

Do you help your mother by providing books, magazines, or papers?

Enrichment

Are there situations where you help your mother learn new hobbies, arts, crafts, or special interests?

Protection

Are there situations where you help your mother protect against crime or danger, such as checking on her health or security?

Psychological Support

Are there situations where you help your mother by listening to problems, and by giving understanding and affection? 
Advice/Information

What kinds of situations or issues might come up where your mother would seek your advice or input?

Housing her?

Do you help your mother by providing living quarters for

I've been asking you about the kinds of help you provide to your mother now, at the current time. How have any of these kinds of help changed as time has gone by? (i.e., what kinds of help do you provide now that you didn't provide in the past, or what kinds of help did you provide in the past that now you do not)?

Can you think of any changes which seem to be due to your mother's working/volunteering?

How do you imagine these kinds of help you provide now might change in the future as your mother gets older?

I've been asking you about the kinds of help you provide for your mother. How do you think your mother's working/volunteering has affected her relationship in general with you? With other family members? (PROBE: How has her work affected how you see her?)

I'm going to return to the list of different types of help that family members sometimes provide for each other, and ask you this time which, if any, your mother provides to you?

\section{* HELP LIST 2}

Homemaking

Are there situations where your mother helps you with homemaking activities such as shopping, cleaning, or preparing meals?

Maintenance

Are there situations where your mother helps you with yard work or by doing household repairs? 
Income

Are there situations where your mother helps you by giving you food or goods needed to live on, or money?

Personal Care

Are there situations where your mother helps you with personal care such as dressing or grooming?

Home Health Care

Are there situations where your mother helps you when you are ill?

Transportation

Does your mother help you with transportation, such as providing a means of getting to work, or visiting your friends, or taking you shopping or to church or to doctor's appointments?

Social and Recreational Activities

Are there situations where your mother helps you with entertaining at home, or getting out for fun, such as accompanying you to special events or meetings?

Employment

Does your mother help you with employment, such as finding a job or a market for goods or services?

Spiritual

Does your mother help you with spiritual or religious activities?

Bureaucratic Mediation

Are there situations where your mother helps you in dealing with government agencies or businesses, such as making phone calls or filling out forms?

Reading Materials

Does your mother help you by providing books, magazines, or papers? 


\section{Enrichment}

Are there situations where your mother helps you learn new hobbies, arts, crafts, or special interests?

Protection

Are there situations where your mother helps you protect against crime or danger, such as checking on your health or security?

Psychological Support

Are there situations where your mother helps you by listening to problems, and by giving understanding and affection?

Advice/Information

What kinds of situations or issues might come up where you would seek your mother's advice or input?

Housing

Does your mother help you by providing living quarters for you?

I've been asking you about the kinds of help your mother provides to you now, at the current time. How have any of these kinds of help changed as time has gone by? (i.e., what kinds of help does your mother provide now that she didn't provide in the past, or what kinds of help did she provide in the past that now she does not provide)?

Can you think of any changes which seem to be due to her working/volunteering?

How do you imagine these kinds of help your mother provides now might change in the future as she gets older?

How do you think her working/volunteering has affects the amount of time she spends with you? With other family members? 


\section{General Attitudes About Older Workers}

In general, do you think working/volunteering is good for older women? How do you think they benefit?

In what situations would it not be appropriate to place older persons as workers or volunteers?

Do you think older workers/volunteers should get more pay or benefits from the work?

\section{Demographic Information}

Before we stop, I have some questions that are usually included in research studies.

What is your date of birth?

Do you work outside the home? Have you in the past? Do/did you work for someone else? Supervise people?

Are you married?

(If married) Does your wife/husband work outside the home? What kind of work does/did she/he do? (Does/did she/he work for someone else? Supervise people?)

(If not married) Separated or divorced? Never Married? Widowed? (If so, how long?)

How many years of formal schooling have you had?

I've completed my questions. Is there anything else that you would like to say that we haven't covered or that you think would be helpful for us to know? 
APPENDIX B

TRAINING MANUAL:

WORK EFFECTS ON MOTHER AND FAMILY 
APPENDIX B

\section{TRAINING MANUAL: \\ WORK EFFECTS ON MOTHER AND FAMILY}

\section{Positive}

A. Sources of Satisfaction (SAT) in work

SATISFACTION- Mother's work provides structure, activity, STRUCTURE something to do or someplace to go during the (SAT-STRUC) day, something to fill time, to be involved in, to organize day, to keep active, involved or busy, or occupy mind or self; or alternative to doing nothing.

- "I'm not much to sit and do nothing and I know it would be hard for me."

-It gets me out of the house and doing things."

- "..the positive side when you are working is that you are doing something."

•"Otherwise she'd be in a rocking chair."

-"It took a lot more of her day up."

•"It keeps her going." ("on the move")

-"You can't just sit in a room and vegetate"

-"It forced her to get out." 
SATISFACTION- Mother has positive affect or good morale, POSITIVE AFFECT improved mental outlook, in relation to or as (SAT-AFF) a result of her work; is happy or interested in, satisfied with, enjoys or loves work. Not working is associated with negative affect.

-"If I weren't working I'd be so bored and crabby."

-"It gives me something I love to do."

-"So, it relaxes me to work at the school."

•"She likes to work."

-When she works, she prospers."

SATISFACTION- Mother's work provides sense of self-esteem, SELF-ESTEEM confidence, feelings of competence or (SAT-EST) ability; not working is associated w/lower selfesteem. SAT-EST is different from SAT-AFF because SAT-EST has to do with a more specific form of feeling good, namely feeling good about self as a result of working. SAT-EST is different from SAT-PUR because SAT-EST has to do with the mental representation of oneself, how one views self, whereas SAT-PUR deals more with mother's view of self in relation to her purpose in the outer world.

-" It has made me feel more confident, and has certainly been helpful to my own self-esteem."

- She feels good about herself when she is working."

SATISFACTION- Mother's work provides a sense of purpose, feelings PURPOSE (SAT-PUR) of productivity, usefulness, sense of doing something worthwhile or of value; allows mother to overcome self absorption or forget about, not dwell upon or worry about own 
problems; not working is associated with feelings of uselessness and/or preoccupation with own problems. (More general, unspecified response than SAT-PUR-SE or SAT-PUR-CH)

-"It takes my mind off my problems."

- She doesn't seem to dwell on her own problems as she used to."

-"(As a result of working) she is not worried about herself."

-When she sits around the house, all she does is think about her problems."

- She can forget about her own problems, it keeps her busy with something else."

SATISFACTION- Mother's work provides a sense of purpose PURPOSE-SERVE specifically in being able to serve clients, serve (SAT-PUR-SE) society, doing work that is helpful, socially meaningful or useful to others.

-I love the children."

-"I feel like those kids really need me."

-"(Working there is worthwhile because)

"these kids really need the love, the guidance, we give them."

SATISFACTION-

Work provides a sense of purpose by PURPOSE-CHALLENGE providing activity that is inherently (SAT-PUR-CH) interesting or challenging. Meaning or value of work tied to the cognitive aspects of work, i.e., taking on responsibility, gaining new knowledge or skills. Includes cultural aspects of work, i.e., learning about different ways of life via clients or staff. 
If there is emphasis on learning, or learning is implied, code SAT-PUR-CH.

-"I am learning some skills."

-"They have all these new ways of doing things there."

-"I couldn't understand the children at first, so it has been a real struggle."

SATISFACTIONSOCIAL-GENERAL (SAT-SOC-G)
Mother's work provides social contact

generally,the experience of being around people and in a social environment.

Recognition of importance of the generalized other (i.e. "people") in the work place. (Note: If there is emphasis on learning or learning is implied, code SAT-PUR-CH). (Note: If there is emphasis on increasing contact with persons outside the family or persons other than family members, code W-IND-SE)

-"Just meeting people, being around other people has been important."

-"The people are so nice, pleasant to be around."

-I just like to be friendly, but I don't want to socialize a lot with the people I work with."

-"Work provides her contact with other people. She has a social outlet."

- Working means she can get out and have a social life."

SATISFACTIONSOCIAL-SPECIFIC (SAT-SOC-S)
Importance of social relationships specifically in the work place, i.e. with coworkers, other staff (excluding clients), working together cooperatively, getting social support from others at work. Specificity can be either in 
how relationships is described (by name or specific role) or in the social interactions described (helping, working together).

(More emphasis on specific aspects of personal relationships than SAT-SOC-G).

-"We really help each other out."

-"The most important thing is my relationship with the teachers."

-"She's wonderful, we work hand in hand."

-"I respect her a lot, she has taught me a lot."

B. Effects of work on mother's independence (W-IND) DERIVED INDEPENDENCE (W-IND)
GENERAL WORK-

Mother's work provides independence (Score only if specific categories of work-derived independence below cannot be used.) [Note: If respondent notes independence of mother generally, i.e., independence that is not specifically derived from or associated with working, score as IND-OW]

-"I guess what I value most from my working is my independence."

WORK-DERIVED Mother's work makes older woman less SOCIAL/EMOTIONAL dependent on family for emotional INDEPENDENCE (W IND-SE) and/or social support; increases contact with others outside of family. Family members may feel relieved or less worried about mother as a result of her working, taking a load off the family. Mother's periods of not working placed social and/or emotional demands or stress on TC and/or other family members. (Note: Use this category when respondent notes generally that work makes. 
older woman less dependent on family but does not specify another kind of work-derived independence, e.g. financial) W-IND-SE differs from SAT-SOC-G because W-IND-SE refers specifically to the positive aspects of decreased involvement with family as a result of mother's work, rather than the positive aspects of being around people in the work place, which is SAT-SOC-G.

- Well I've gotten part time work. Got to be on my own. Got out of her hair...where I didn't have to depend on someone else."

- I think not working affects us more...when I'm down and out and hurting it affects them too, they don't like that."

WORK-DERIVED FINANCIAL INDEP. (W-IND-PAY)
- If older persons didn't work they'd be depending on their family too much."

Mother's work provides economic rewards, e.g., pay or benefits (health insurance, meals). Indicates financial independence or means of survival, security, or support; mother's periods of not working placed financial demands or stress on adult child and/or other family members.

- I want to stay independent and be able to buy things that help me, really make things easier for me around the house, such as a lawnmower."

-"They don't have to worry about whether I have food on the table."

-"I now work so I can pay my bills, but at a time I had to ask my children for money." 
- A woman has to maintain her own livelihood."

- We expect that she should have a job and support herself."

WORK- DERIVED PHYSICAL INDEPENDENCE (W-IND-PHY)
Mother's work promotes or indicates physical health of older woman; indicates youthfulness or being younger than years.

-I think they feel at my age they should be helping me across the street...but the fact that I've been able to do this kind of work has changed all that."

- I think he's surprised that I'm physically able to do what I do."

- She is not impaired physically from working, and she needs the physical activity."

-"Working keeps her healthy."

C. Other Effects of work on mother's relationship with family

IMPROVED RELAT- Mother's work improves relationship

IONS

(IMP-REL) w/adult child and/or other family members. Score only if respondent notes explicitly that relationship of mother with adult child and/or other family members has benefitted, been improved or made easier by mother's working.

-"I think I have a better relationship with them than if I were just at home here."

-"Since I've been working it's opened up 
a new area in my life. I feel like my relationship with my family has really improved, too."

-"She's easier to get along with."

- Her working has made family life easier for all of us."

TIME POSITIVE (TIME-POS)
Mother's work enhances or improves time spent, increases quality time with adult child and/or other family members.

-"I think I'm more relaxed to spend time with them."

- Since I've been working our time together has been really special."

-"I think that since she started working I've valued our time together more."

-"I look forward to our time together."

IMPROVED COM- Mother's work improves communication with MUNICATION adult child and/or other family members; (COMM) provides topics of conversation and basis for shared understanding.

-"The good part about it is that I have something to say...I'm working with people all day long and I discuss that with her."

-"The positive thing is that I'm working and we can speak on that level, about people and, you know, general different stuff. We both talk about our job and stuff."

-"I think she is much more understanding of my problems."

-"It gives her something to talk about." 
OTHER ESTEEM (O-EST)
Adult child and/or other family members (exclude persons in work place) feel positive, glad, or happy about, proud, admiring, or appreciative of mother's working.

-"I think he's proud of me."

- She's glad I'm doing it. In fact they appreciate it, all of them."

- It makes me feel happy about her. I think it's good."

-"to be working at her age...I have a lot of admiration for her.

\section{Negative}

WORK-DERIVED Mother's work decreases the amount of time spent TIME DECREASE w/adult child and/or other family members; score (W-TIME-DEC) only if nature of time (e.g., visits, child care) unspecified; mother's work together with her other responsibilities fills her time or leaves her time for little else.

-I'm not here all the time anymore."

-"Well, since I'm working, all I can do is go to work, come home, take care of my yard, take care of whatever I have to take care of."

-"Oh, it's definitely affected the amount of time I spend with them...

WORK-DERIVED VISITS-DECREASE (W-VIS-DEC)
Mother's work interferes with or decreases visits, getting together, or phone conversations with adult child or other family members; mother's work makes it more difficult to coordinate or schedule visits or 
phone calls with adult child or other family members.

- So I don't see them and I don't get together with them as much as I should maybe, or as much as I used to."

-"So it keeps me from visiting with them very much, only on holidays or something like that...It's hard to catch me..."

WORK-DERIVED Mother's work decreases her availability for care CHILDCARE DECREASE (W-CC-DEC) of, or time spent with, grand-/great-grandchildren.

-"Maybe if I hadn't been working, he would have had less problems with T. (grandchild), because I probably could have cared for $T$. more, but there were times I had to say no."

-"It does affect it, because I can't baby-sit during the day for them anymore."

-"I used to substitute teach, but now that Mom's working and can't sit with my son anymore, I've had to stop."

- She used to stay with my children pretty regularly, but her working has changed all that."

WORK-DERIVED Mother's work decreases her availability to provide INSTRUMENTAL instrumental help and/or support (other than child DECREASE (W-INST-DEC) care) to adult child and/or other family members.

-"I used to help her with the canning, but there's just no time for that now."

- Before she got her job she would give me a ride to my weekly doctor's appointment but now I take the bus instead." 
-"She used to help me with the cleaning, but since she started working she doesn't help out anymore."

ADULT CHILD'S Adult child works, is busy, has limited time; WORK (AC-WK) adult child's work or being busy interferes with, decreases family visits or time spent together.

- The negative part is that my daughter works very, very hard, she has a very stressful job, which I wouldn't have on a silver platter, she's a credit manager."

-...If my son wasn't so busy there might be more getting together."

- I work shifts and get off at odd hours. used to go by there (visit mother) all the time, but now I have to go home and feed my dog."

PHYS/EMOTIONAL Mother's work is tiring, creates health or STRESS (W-STRES) other problems, physical and/or emotional stress; working is hard on mother; mother dislikes working; $\mathrm{TC}$ is concerned or worried about mother because of working.

-"I work not very hard, but it's mind boggling 'cause you're trying to find people jobs that are 55 and older, and so you, you know, I'm tired, too."

-"I sometimes lift the children, who can be quite heavy, from their wheelchair onto my lap. I know I'm not supposed to, but there's not always an attendant available."

-"She worries about me and says--I don't want you to work anymore." 
- She gets moved around a lot-how are you going to feel positive about that?"

-"She doesn't like working."

\section{Neutral}

ALWAYS WORKED (AW)

NO WORK/FAMILY EFFECT

(NO W/F)
Mother has always worked.

-"I've always worked, so he's used to that."

-I'd worked for the past twenty years as a secretary before becoming a Foster Grandma. My children have never known me not to work."

Mother's work has no effect on the family. Use this category to score work/family effect questions only if no other work effects category mentioned.

-"I don't think that my work has affected the amount of time I see my children. No, I can't see any difference."

- We've always gotten together on Sundays after church. Nothing has changed since I started work." 